\title{
LA DISTINCIÓN ENTRE HECHO Y VALOR: LA DOCTRINA DE LOS DOS MUNDOS Y EL SENTIDO INMANENTE Hans Kelsen como neokantiano*
}

\author{
Stanley L. Paulson** \\ Washington University
}

\section{Introducción: dos enfoques sobre la normatividad en el derecho}

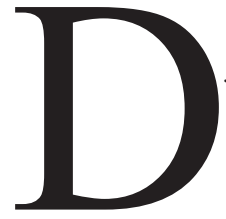

e acuerdo con Hans Kelsen (1881-1973), la tesis de la facticidad o de la reducción se refleja en la filosofía del derecho y en la teoría jurídica de muchos de sus antecesores y contemporáneos. Según esta tesis, el derecho se explicita en última instancia recurriendo a un fenómeno social, que bien puede ser la voluntad del soberano o la aceptación del ordenamiento jurídico y sus normas por parte de sus destinatarios. Si la tesis de la facticidad se extrapola a categorías semánticas, puede decirse que los teóricos del derecho que defienden una posición reduccionista, introducen "definiciones eliminatorias", en virtud de las cuales, reemplazan los conceptos normativos del derecho por conceptos correlativos de tipo descriptivo. La idea de que en esto consiste el discurrir de la ciencia jurídica puede llamarse "tesis semántica reduccionista". La convicción de Kelsen de que esta tesis era errada,

* Traducción de Carlos Bernal Pulido, profesor de filosofía del derecho y derecho constitucional de la Universidad Externado de Colombia (Bogotá), del original en alemán publicado en R. Alexy, L. H. Meyer, S. L. Paulson y G. Sprenger (Edt.), Neukantianismus und Rechtsphilosophie, Nomos, Baden-Baden, 2002, p. 223-251.

** He tenido la oportunidad de presentar a modo de conferencia, anteriores versiones de este artículo en Kiel (julio de 2000), en la Conferencia del grupo de Bielefeld, en Viena (diciembre de 2000) y en León (mayo de 2001). Quisiera agradecer a Robert Alexy, Martín Borowski y Carsten Heidemann en Kiel, Juan Antonio García Amado, Carlos Bernal Pulido y Miguel Ángel Rodilla en León y Salamanca, Stefan Hammer y Alexander Somek en Viena, Christian Krijnen en Mannheim, Lukas H. Meyer en Nueva York y Bremen, Bonnie Litschewski Paulson en St. Louis y Martín Schulte en Dresden por sus valiosos comentarios. La Fundación Alexander von Humboldt (Bonn-Bad Godesberg) financió este trabajo durante una estancia de investigación de tres meses.

1 Joseph Raz, "The Purity of the Pure Theory", en: Normativity and Norms. Critical Perspectives on Kelsenian Themes, Stanley L. Paulson y Bonnie Litschewski Paulson Edt., 1998 (en lo sucesivo: Normativity and Norms), p. 237-252 (239). Sobre esta interpretación de la filosofía del derecho de Kelsen, Cfr. También Joseph Raz, "Kelsens Theory of the Basic Norm", en id., p. 47-67. 
determina el rumbo de su filosofía del derecho ${ }^{2}$, sobre todo en su primera fase, la preclásica ${ }^{3}$. Como el propio Kelsen enfatiza retrospectivamente: "En los "Problemas capitales de la doctrina del derecho del Estado" se trata en primer lugar de encontrar la singularidad del derecho frente a la de la naturaleza o frente a la de una realidad social determinada de un modo similar a la naturaleza"4. En lugar de la tesis de la facticidad, Kelsen defendió desde el comienzo la tesis de la normatividad -es decir, una tesis semántica no reduccionista-.

Tanto en relación con la obra de Kelsen, como también más allá de ella, existen en la literatura de la filosofía del derecho las más diferentes interpretaciones de la tesis semántica no reduccionista o tesis de la normatividad 5 . Una caracterización del enfoque normativo, que a mi juicio resulta ejemplar, proviene de Joseph Raz:

${ }^{2}$ Cfr. Sobre este aspecto, en general: Stanley L. Paulson, "Konstruktivismus, Methodendualismus und Zurechnung im Frühwerk Hans Kelsens", en: Archiv des öffentlichen Rechts 124, 1999, p. 631-657 (en lo sucesivo: "Konstruktivismus, Methodendualismus und Zurechnung"). (Tiene traducción al castellano en: Stanley L. Paulson, "Constructivismo, dualismo metódico e imputación en la obra inicial de Hans Kelsen”, en Id., Fundamentación crítica de la doctrina de Hans Kelsen, Traducción de Luis Villar Borda, Universidad Externado de Colombia, Bogotá, 2000).

${ }^{3}$ La primera fase de Hans Kelsen, que puede denominarse "constructivismo crítico", tiene su más clara expresión en su primera gran obra, publicada en el año 1911, el escrito de habilitación Problemas capitales de la doctrina del derecho del Estado (Hauptprobleme der Staatsrechtslehre) (en lo sucesivo: Hauptprobleme). En esta primera fase, Kelsen trata sobre todo de construir un conjunto de conceptos no reduccionistas, para responder al positivismo jurídico y estatal de vieja laya, que siempre se había basado en lo fáctico. La segunda fase, clásica o neokantiana, que transcurre aproximadamente desde 1920 hasta 1960, puede caracterizarse con base en dos desarrollos que ya se habían llevado a cabo a mediados de los años veinte. De un lado, Kelsen intenta fundamentar, por lo menos parcialmente, los conceptos básicos del derecho mediante una argumentación trascendental. Las particularidades de dicha argumentación pueden exponerse con ayuda de diferentes doctrinas que se remontan hasta Kant y los neokantianos. De otro lado, ya al comienzo de los años veinte Kelsen, adoptó la totalidad de la doctrina del escalonamiento jurídico (Stufenbaulehre) de Adolf Julius Merkl. La concepción estática, presentada en los "Hauptprobleme", que sólo estaba compuesta por normas jurídicas generales, fue remplazada por Kelsen por una concepción "jurídico-dinámica”, en virtud de la cual, las normas jurídicas progresan "en una concreción escalonada que va desde la Constitución [...] hasta los actos jurídicos individuales de ejecución”. Id., 2a . Edición, con nuevo prólogo, 1923, p. XV. A comienzos de los años cuarenta comienza Kelsen a introducir en su filosofía del derecho algunos componentes analíticos y empíricos, sin renunciar, sin embargo, a la argumentación neokantiana. Luego, aproximadamente en 1960, Kelsen sustituye por completo su instrumental neokantiano por una teoría voluntarista del derecho, más bien poco disfrazada, en la que asume auténticas posiciones escépticas. Entre ellas se encuentran, por ejemplo, las reservas sobre la aplicabilidad de la lógica al derecho. Esta fase escéptica es la tercera y última, que va hasta la muerte de Kelsen.

${ }^{4}$ Hans Kelsen, Hauptprobleme (citado en la nota núm. 3), 2a . Edición con nuevo prólogo, 1923, p. VI. La cursiva es del original.

${ }^{5}$ Cfr. Por ejemplo, los artículos publicados en Normativity, J. Dancy Edt., 2000. 
"Algunos aspectos del mundo son normativos, en la medida en que constituyen [...] razones para las personas, y específicamente, razones que hacen que ciertas orientaciones, sentimientos, emociones, intenciones o comportamientos sean apropiados o inapropiados. ${ }^{\prime 6}$

Una caracterización semejante de la normatividad plantea numerosos interrogantes. ¿Cómo es posible que algunos "aspectos del mundo" funcionen como razones a favor de ciertas orientaciones, comportamientos y fenómenos similares? Aunque no pueda ofrecerse respuestas totalmente satisfactorias para preguntas como ésta, es imposible soslayar el punto de partida de esta tesis de la normatividad: lo característico de la normatividad es el poder aducir razones a favor de una acción. Si se aducen adecuadamente las razones, éstas fundamentan la acción de que se trate. En el contexto institucionalizado del derecho, la tesis de la normatividad se refiere por antonomasia a las obligaciones de los sujetos, a llevar a cabo u omitir determinadas conductas, y las razones para atribuir a alguien dichas obligaciones y reconocerles carácter vinculante.

Aquí se plantea la pregunta de si Kelsen entiende por normatividad algo semejante. De acuerdo con una de las posibles interpretaciones de su obra, este autor concibe la normatividad como la "sustancia intelectual" del derecho y de sus normas.

"[La Teoría pura del Derecho] es bien consciente de que el significado normativo especifico de ciertos hechos materiales, el significado de aquello que se designa como 'Derecho', no es el resultado de una interpretación necesaria, sino de una interpretación posible, que se origina sólo a partir de cierta presuposición básica [...]. Sin embargo, la Teoría pura del Derecho no considera que de ello se derive necesariamente la consecuencia de que deba renunciarse a la categoría del deber ser y, de este modo, a una teoría normativa del Derecho, es decir, a una exploración epistemológica y a un tratamiento sistemático de la sustancia intelectual que se origina a partir de los actos naturales, para así otorgarles sentido jurídico. "

Si se considera la caracterización que Raz hace de la normatividad como la tesis fuerte de la normatividad, entonces, bien puede entenderse que la caracterización de Kelsen es más débil. Su enfoque trata de concebir las normas jurídicas como algo sui generis ${ }^{8}$, como entidades que tienen validez en una

${ }^{6}$ Joseph Raz, "Explaining Normativity: On Rationality and the Justification of Reason", en: Ibíd., p. 34-39 (34) Id., Engaging Reason. On the Theory of Value and Action, Oxford: OUP, 1999, p. 67-89 (67).”

${ }^{7}$ Kelsen, Reine Rechtslehre, 1. Edición. (citado en la nota núm. 1), § 16 (p. 36 y ss.) (Tiene traducción al castellano: Teoría pura del derecho, Eudeba, Buenos Aires, 1999). Sobre la normatividad en la teoría del derecho de Kelsen, Cfr. También la amplia exposición de Carsten Heidemann, Die Norm als Tatsache. Zur Normentheorie Hans Kelsens, Baden-Baden 1997.

${ }^{8}$ Cfr. Alf Ross, Towards a Realistic Jurisprudence, traducción de Annie I. Fausbøll, 1946, p. $39-48$. 
esfera separada del mundo exterior y que por lo tanto no permiten ser reducidas a meros hechos. Dicho de otra forma, este enfoque parte de la concepción de las normas jurídicas como contenidos objetivos de sentido ${ }^{9}$, una interpretación que puede fundamentarse apelando a una concepción neokantiana. Más adelante se volverá sobre este punto. Esta tesis de la normatividad es en realidad mucho más débil que la expuesta anteriormente, porque lo único relevante en ella es que la norma jurídica puede resistirse a todo intento de reducirla a algo fáctico. Un problema por entero diferente es establecer si existe una fundamentación semejante que pueda vincularse a la norma jurídica.

De muy distintas maneras los filósofos del derecho han intentado presentar la teoría del derecho de Kelsen por medio de la tesis fuerte de la normatividad $^{10}$. No es fácil decidir si esta empresa puede llevarse a cabo con éxito. En esta investigación me ocuparé sólo de los fundamentos filosóficos de la normatividad, tal como Kelsen la entiende, es decir, como la contrapartida de la facticidad. Dado que las dos tesis de la normatividad comparten este última propiedad, el análisis de la tesis débil de la normatividad resulta suficiente para los fines de esta investigación.

Con todo, el enjuiciamiento de la tesis fuerte de la normatividad no resulta tan fácil como puede parecer a primera vista. La razón de ello se encuentra en que esta tesis se relaciona con la doctrina de los dos mundos, de la que a su vez se origina una profunda antinomia que afecta a la teoría del derecho de Kelsen: ambos mundos, el exterior y el normativo (o el de la validez), se separan herméticamente el uno del otro - esto crea una situación antinómica en la que el propio Kelsen insiste- $-{ }^{11}$. La respuesta para la pregunta de si esta antinomia puede resolverse desde el enfoque de Kelsen, presupone emprender una investigación de sus fuentes filosóficas en este área del conocimiento. Su propia contribución al desarrollo de aquello que conduce a dicha antinomia, debe calificarse en realidad como insuficiente. Entre las fuentes filosóficas de la Teoría pura del derecho de Kelsen se encuentra sobre todo el neokantismo.

En el apartado I introduciré la distinción entre hecho y valor y argumentaré que es ésta -y no la particular distinción iusfilosófica entre el ser y el

\footnotetext{
${ }^{9}$ Cfr. Las citas referenciadas en las notas núm. 130-131.

${ }^{10}$ A pesar de que por ejemplo Robert Alexy, Begriff und Geltung des Rechts, 2. Edición, 1994, p. 155-186 (tiene traducción al castellano: El concepto y la validez del derecho, Gedisa, Barcelona, 1994); Joseph Raz (citado en la nota núm. 1), y Carlos Santiago Nino, "Some Confusions surrounding Kelsen's Concept of Validity", en: Normativity and Norms (citado en la nota núm. 1), p. 253-261, defienden muy diferentes interpretaciones de Kelsen, en los tres casos se trata de variantes de la tesis fuerte de la normatividad.

${ }^{11}$ Cfr. Apartado II infra.
} 
deber ser- aquélla que juega el papel fundamental en las doctrinas sobre la filosofía y la teoría del derecho de los antecesores y contemporáneos de Kelsen, así como en la crítica de este autor hacia dichas doctrinas. En el apartado II expongo la antinomia que se deriva de la teoría de los dos mundos y que subyace a los planteamientos de Kelsen. El apartado III se dedica a la pregunta: ¿Qué clase de neokantiano fue Kelsen? Mediante varias comparaciones materiales y citas bibliográficas intento mostrar que, en aspectos centrales, su filosofía del derecho recibió una considerable influencia sobre todo del neokantismo del Baden o del suroeste de Alemania ${ }^{12}$. En el apartado IV vuelvo a referirme a la antinomia, desde la perspectiva de las teorías iusfilosóficas de Kelsen, acuñadas con el sello del neokantismo. En la medida en que pueda afirmarse que la antinomia se puede resolver con la intermediación de la teoría del sentido inmanente -el problema tiene muchas aristas, y aquí sólo puede esbozarse uno de los posibles enfoques de solución-, se satisface una condición necesaria para poder defender la tesis débil de la normatividad. Pero aún más extendido es el alcance de la conclusión que subyace al enfoque utilizado para resolver la antinomia: el propio Hans Kelsen es un neokantiano con impronta de la escuela del Baden, y, por tanto, resulta completamente coherente y útil la idea de que los problemas que se originan a partir de su filosofía del derecho pueden solucionarse apelando al instrumental del neokantismo de la escuela del Baden.

\section{La diferencia entre ser y deber ser como la distinción entre hecho y valor}

Con frecuencia se acepta que la tradición iusfilosófica occidental puede comprenderse de la mano de dos tesis. En la terminología de hoy, ellas son, por una parte, la tesis moral o tesis de la vinculación y, por otra parte, la tesis de la separación ${ }^{13}$. La tesis de la separación señala que el derecho y la moral pueden separarse conceptualmente, o, en otras palabras, que no existe una conexión necesaria entre el derecho y la moral. La tesis moral o de la vinculación establece exactamente lo contrario, o sea, que en verdad existe una conexión necesaria entre el derecho y la moral. Si la idea se formula

${ }^{12} \mathrm{El}$ interrogante sobre la influencia de la escuela del Baden en Kelsen ha sido siempre soslayado. Dos importante excepciones en este campo son los trabajos de Carsten Heidemann, Die Norm als Tatsache (citado en la nota núm. 7), especialmente las p. 51-55, 222-224, y Stefan Hammer, “A Neo-Kantian Theory of Legal Knowledge in Kelsen's pure Theory of Law?", en: Normativity and Norms (citado en la nota núm. 1), p. 177-194.

${ }^{13}$ Un esbozo clásico bien conocido, cuya lectura aún tiene valor es: Xenophon, Erinnerungen, I. ii. 40-46, moderna edición en alemán: Xenophon, Die Sokratischen Schriften, traducción de Ernst Bux, 1956, p. 59 y ss. Para una exposición actual es recomendable: Robert Alexy, Begriff und Geltung des Rechts (citado en la nota núm. 10). 
correctamente, a partir de la conjunción de la tesis moral o de la vinculación y la tesis de la separación, aparece entonces con claridad una contradicción. Entonces, la contraposición que se plantea entre estas dos tesis iusfilosóficas es fundamental para determinados fines analíticos, ante todo, porque las dos tesis pueden constituir el punto de partida para precisar en qué consiste el problema de la relación entre el derecho y la moral ${ }^{14}$.

Esta contraposición clásica es el fiel reflejo de una distinción entre el ser y el deber ser, en la cual, el "ser" se relaciona con el derecho válido y el "deber ser" con las normas de la moral. Esta es la distinción entre ser y deber ser propia de la filosofía del derecho. Con todo, observada desde la perspectiva histórica, esta contraposición no refleja la evolución completa de la filosofía del derecho y de la teoría general del derecho durante el Siglo XIX. En realidad, fue una segunda diferenciación entre el ser y el deber ser la que jugó el papel protagónico en aquél entonces. En esta segunda diferenciación, el "ser" se relaciona con los hechos del mundo exterior, al paso que el "deber ser" tiene que ver con las normas de la moral y del derecho. Esta segunda distinción entre el ser y el deber ser se conoce generalmente con el apelativo de "distinción entre hecho y valor", que se remonta a David Hume ${ }^{15}$, así como con la denominación de "dualismo metodológico"16. A continuación quisiera presentar sucintamente esta distinción, como quiera que de ella se deriva el enfoque normativo de Kelsen.

\footnotetext{
${ }^{14}$ Robert Alexy diferencia entre el observador y el participante, lo conceptual y lo normativo, etc., y llega, en un Tour de Force, a 64 posibilidades imaginables en que se puede entender las tesis moral o de la vinculación y de la separación. Aun cuando algunas de estas posibilidades de interpretación no son aplicables en la práctica -lo cual es aceptado por Alexy sin ningún reparo-, sus observaciones muestran de manera clara y explícita todo lo que se puede originar desde ese punto de partida, cuando se complementa con una serie de diferenciaciones adicionales. Cfr. Ibíd., p. 39-136, especialmente las p. 49-51.

${ }^{15}$ Cfr. David Hume, A Treatise of Human Nature (primera publicación: 1739-40), editado por D.F. Norton y M. J. Norton, 2000, libro III, primera parte, apartado primero (p. 302).

${ }^{16}$ Gustav Radbruch, Rechtsphilosophie, 1932, § 2 (especialmente p. 6 - 9), reproducido en: Id, Gesamtausgabe, Edt. por Arthur Kaufmann, Tomo 2: Rechtsphilosophie II, 1993, § 2 (especialmente p. 230 - 233). Cfr. También Max Weber, "Roscher und Knies und die logischen Probleme der historischen Nationalökonomie (3. artículo): Knies und das Irrationalitätsproblem (continuación), en: Schmollers Jahbuch für Gesetzgebung, Verwaltung und Volkswirtschaft im Deutschen Reich 30, 1906, p. 81-120, especialmente p. 102 y ss., nota 1, reimpreso en: Id, Wissenschaftslehre, 6 edición., Edt. por Johannes Winckelmann, 1985, p. 105-145, especialmente p. 127 nota 1; Max Weber, "Der Sinn der "Wertfreiheit" der soziologischen und ökonomischen Wissenschaften”, en $\log o s$ 7, 1917/18, p. 40-88, especialmente p. 51, reimpreso en: Id, Wissenschaftslehre (citado en esta nota), p. 489-540, especialmente p. 501. Como H. H. Bruun en su clásica obra Science, Values and Politics in Max Weber's Methodology, 1972, p. 23, acertadamente apunta, Weber considera la distinción entre ser y deber ser como una obviedad y por ello no se ocupa de su fundamento filosófico.
} 
Refiriéndose al antagonismo entre las leyes de la naturaleza y las normas, Kelsen expone su distinción entre ser y deber ser de la siguiente manera:

"Un completo antagonismo entre las leyes de la naturaleza y las normas sólo es posible en razón de una completa disparidad entre ser y deber ser. Así como puedo afirmar sobre algo: ello es, así también puedo decir de lo mismo: ello debe ser, y en cada caso habré dicho algo totalmente distinto" 17

Ser y deber ser son las más generales disposiciones del pensamiento, aclara Kelsen ${ }^{18}$, o -siguiendo a Georg Simmel- modalidades fundamentales del pensamiento. En este punto Simmel compara estas modalidades con las categorías gramaticales: el futuro y el pretérito, el conjuntivo y el optativo ${ }^{19}$. Ser y deber ser sí serían fundamentales como las categorías gramaticales puras, porque serían modalidades elementales, en las que lo indicativo, por una parte, y lo normativo, por otra, no se reflejan mutuamente en modelos deductivos intercambiables. En palabras de Simmel que Kelsen aprueba y cita, la distinción entre hecho y valor se expresa de la siguiente manera:

"El ser nunca (puede) deducirse de meros conceptos, sino sólo de aquellos en los que de alguna manera el ser ya está contenido. El deber ser se comporta de la misma forma. Que nosotros debamos hacer algo, sólo puede demostrarse mediante una reducción a otro deber ser seguro, ya presupuesto (...)"20.

Debido a su empeño, a veces un poco extraño, de debatir la tesis de la facticidad, Kelsen apela constantemente a la distinción entre hecho y valor ${ }^{21}$. Si se parte de que el derecho puede "reconocerse específicamente en las leyes singulares a las que obedece y sin alusión a las leyes de la naturaleza"22, entonces el recurso al material fáctico debería considerarse como uno de los ejemplos más graves de sincretismo metodológico, es decir, de vulneración del ideal metodológico de la pureza ${ }^{23}$.

\footnotetext{
${ }^{17}$ Hans Kelsen, Hauptprobleme (citado en la nota núm. 3), p. 7.

18 Ibíd.

${ }^{19}$ Georg Simmel, Einleitung in die Moralwissenschaft, 2 Tomos, 1892/93, Tomo 1, p. 12, reimpreso en Id, Gesamtausgabe, Tomo 3, 1989, p. 22, citado en: Hans Kelsen, Hauptprobleme der Staatsrechtslehre (citado en la nota 3), p. 7 y ss.

${ }^{20}$ Georg Simmel, Einleitung in die Moralwissenschaft, (citado en la nota 19), tomo 1, p. 12, reimpreso en Id., Gesamtausgabe, Tomo 3, 1989, p. 25, citado en: Hans Kelsen, Hauptprobleme der Staatsrechtslehre (citado en la nota 3), p. 8. (No se ha trascrito el énfasis de Kelsen).

${ }^{21}$ Cfr. P. Ej. Hans Kelsen, Allgemeine Staatslehre, 1925, § 2 (p. 6 y ss.), $\$ 5$ (c) (p. 18 y ss.), § 13 (b) (p. 62 y ss.), § 15 (c) (p. 73), § 20 (a) (p. 102 y ss.), § 38 (d) (p. 269 y ss.), § 44 (b) (p. 322 y ss.).

${ }^{22}$ Hans Kelsen, Der soziologische y der juristische Staatsbegriff, 1922, § 12 (p. 81). (La cursiva es del original).

${ }^{23} \mathrm{El}$ ideal metodológico de la pureza puede reconducirse conceptualmente a la caracterización kantiana de los conocimientos como "puros", cuando "no contienen absolutamente nada empírico". Inmanuel Kant, Kritik der reinen Vernunft, 1781/87, Tomo 3. Especialmente en el contexto del constructivismo jurídico, la "pureza" se relaciona con la pretensión de evitar la
} 
De manera antagónica a la distinción entre hecho y valor, la separación entre derecho y moral, en el sentido de la tesis de la separación característica del positivismo jurídico - la tesis contraria a la tesis moral o de la vinculación, según la distinción entre ser y deber ser propia de la filosofía del derecho- sólo se admitió vagamente, si acaso lo fue de algún modo, entre los antecesores y contemporáneos de Kelsen. En primer lugar, a diferencia de sus colegas ingleses de esta época, ninguno de los teóricos del derecho del Siglo XIX del ámbito continental-europeo defendió una ética similar a la del utilitarismo, cuyos principios y exigencias debieran separarse tajantemente de las normas jurídicas. A lo largo del siglo XIX, los teóricos del ámbito continental-europeo se ocuparon más bien de otros proyectos totalmente diversos, a saber, de la configuración científica del derecho y de todo lo que implica este proyecto: sistema, estructura conceptual y otros aspectos similares $^{24}$. Este Leitmotiv, o sea, la configuración científica del derecho, y la carencia de una ética filosófica por parte de los teóricos del derecho del ámbito continental europeo de aquél entonces, condujo a que no vieran ningún motivo para ocuparse de la tesis de la separación.

Aun cuando el teórico del derecho continental-europeo hubiese defendido una ética filosófica, esto no habría implicado nada con respecto a su aplicación a la tesis de la separación, a menos que se hubiese apartado de la tesis de la facticidad. Esta consideración, que constituye la segunda razón para que la tesis de la separación no jugara un papel relevante entre los antecesores y contemporáneos de Kelsen, puede explicarse si se alude a la situación de la teoría general del derecho que entonces predominaba en Inglaterra. Allí sí se hallaba la tesis de la separación en los escritos de John Austin y sus sucesores, pero jugaba un papel subordinado frente a la distinción entre hecho y valor. En esto puede haber sucedido algo que se explica mediante un argumento de dos partes. Por una parte, el supuesto material normativo del derecho podría reducirse a estados de cosas fácticos, y por

mezcla de diferentes métodos cognitivo-teoréticos. Georg Jellinek da un prominente testimonio de este intento por erradicar este "vicio": "Si se ha comprendido la distinción general entre el mundo de las ideas de los juristas y el mundo objetivo de los sucesos de la naturaleza, entonces de ello se deriva la inadmisibilidad de una extrapolación a aquéllas, de los métodos para el conocimiento de estos últimos. Entre los vicios científicos de nuestro tiempo se encuentra el del sincretismo metodológico". Georg Jellinek, System der subjektiven öffentlichen Rechte, 2. Edición, 1905, reimpresión de 1979, p. 17. Ciertamente, en nombre de la pureza, Kelsen se sale del marco trazado por Jellinek y va mucho más allá. Cfr. El texto citado en las notas núm. 33 y 34 .

${ }^{24} \mathrm{Cfr}$. En general sobre este aspecto: Michael Stolleis, Geschichte des öffentlichen Rechts in Deutschland, Tomo 2: Staatslehre und Verwaltungswissenschaft 1800-1914, 1992, p. $322-$ 380; Walter Pauly, Der Methodenwandel im deutschen Spätkonstitutionalismus, 1993; Christoph Schönberger, Das Parlament im Anstaltsstaat, 1997, p. 21-182. 
otra, dichos estados de cosas fácticos serían suficientes en definitiva para explicar el supuesto material normativo del derecho. Sin embargo, si los meros hechos fuesen suficientes para aportar las explicaciones necesarias, entonces la moral podría considerarse como algo innecesario. De este modo, la introducción de la tesis de la separación se convertiría en algo superfluo.

No es entonces casual que John Austin dedicara una relevante parte de la sexta de sus "Lectures on Jurisprudence" ${ }^{25}$ a aquéllos estados de cosas fácticos a lo que puede reconducirse la soberanía como un concepto jurídico, mientras que este mismo autor restringiera la cita que después sería entendida como una introducción de la tesis de la separación ${ }^{26}$, a sólo algunos pasajes $^{27}$.

$\mathrm{Si}$ estos argumentos son acertados, debe concluirse que, desde una perspectiva histórica, la diferencia básica del Siglo XIX no fue entonces la contraposición iusfilosófica entre el ser y el deber ser, sino la distinción entre hecho y valor. Es evidente que no todos los autores que precedieron a Kelsen o fueron sus contemporáneos, y que fueron criticados duramente por este

${ }^{25} \mathrm{Al}$ comienzo de su sexta lección, Austin aclara que pretendía descomponer diversos conceptos, entre ellos el de soberanía. A partir de ahí se origina un análisis en el que Austin descubre que esta construcción, hasta entonces concebida como un concepto normativo, era una circunstancia puramente fáctica. Esta reducción, llevada a cabo por Austin, se observa de manera patente en su reducción del concepto de soberanía a dos condiciones fácticas: "Aquella forma de dominación suprema que se designa con el concepto de soberanía, junto con la comunidad política independiente que está ligada a ella, se diferencia de otras formas de dominación suprema y, de este modo, de otras formas de comunidad, en las siguientes características o propiedades:

1. Hay una instancia suprema (persona o corporación), que es reconocida de manera idéntica y unívoca por toda la sociedad y que es obedecida habitualmente por la gran mayoría de la población.

2. Esa persona o corporación no obedece habitualmente, por su parte, a ninguna otra instancia superior."

Austin, Lectures on Jurisprudence, 5. edición, Editada por Robert Campbell, 2 tomos, Londres 1885, Tomo 1, Lecture 6, p. 220. La crítica de Kelsen a la teoría jurídica de John Austin tiene lugar en el marco de la distinción entre hecho y valor. Cfr. Hans Kelsen, "The Pure Theory of Law and Analytical Jurisprudence“, en: Harvard Law Review 55, 1941/42, p. 44-70 (54), reimpreso en: Id, What is Justice?, 1957, p. 266-287, (p. 271 y ss.).

${ }^{26}$ Fue sobre todo H.L.A. Hart, quien, refiriéndose a los escritos de Jeremy Bentham y John Austin, introdujo la tesis de la separación en la discusión actual. Cfr. H.L.A. Hart, "Positivism and the Separation of Law and Morals", en Harvard Law Review 71, 1957/58, p. 593-629, especialmente las p. 594-600.

${ }^{27}$ Entre otros, aduce Austin: “Ahora bien, decir que las leyes humanas que se enfrentan a las leyes divinas no son vinculantes, es decir, que no son leyes, es decir una tontería. Las leyes más nocivas, y por tanto aquéllas más opuestas a la voluntad de Dios, han sido y son cotidianamente aplicadas por los tribunales de justicia". John Austin, Lectures on Jurisprudente (citado en la nota núm. 25), Lectura 5 (p. 215). (La traducción está tomada de la versión en castellano: El objeto de la jurisprudencia, Centro de Estudios Políticos y Constitucionales, Madrid, 2002, p. 189.) 
último en nombre de la distinción entre hecho y valor -por ejemplo, Ernst Rudolf Bierling, Karl Binding, Eugen Ehrlich, Carl Friedrich von Gerber, Otto von Gierke, Alexander Hold v. Ferneck, Georg Jellinek, Rudolf von Jhering, Hermann Kantorowicz, Hugo Preuss, Gustav Radbruch, Felix Somló, Rudolf Stammler, August Thon, Max Weber, Bernhard Windscheid y Ernst Zitelmann, un poco más tarde Carl Schmitt y Rudolf Smend, y finalmente John Austin y Alf Ross- defendieron una teoría basada en lo fáctico. ${ }^{28} \mathrm{En}$ realidad sucedió todo lo contrario, pues entre los muchos autores criticados, tal vez sólo puede considerarse a John Austin y Felix Somló, como representantes de la tesis de la facticidad ${ }^{29}$. Con todo, esta circunstancia no fue óbice para que Kelsen criticara a todos los demás autores mencionados, a causa de que supuestamente propugnaban una doctrina basada en lo fáctico. Es necesario comprender de un modo un poco desfigurado algunas de las doctrinas tomadas en consideración, para ver en ellas una aplicación de la tesis de la facticidad. Un ejemplo de ello es la interpretación que hace Kelsen de la teoría jurídica de Rudolf Stammler ${ }^{30}$. Stammler introdujo y aplicó métodos cognitivos fundamentalmente diversos, que además se excluían entre sí: uno teleológico y uno causal ${ }^{31}$. De acuerdo con Kelsen, el método teleológico de Stammler podría reducirse al causal, con lo cual, la teoría de Stammler en general se caracterizaría únicamente por medio de este último método ${ }^{32}$.

En otros casos, después de un análisis más detenido puede llegar a verse que el teórico del derecho criticado por Kelsen en realidad no se alejaba tanto de la tesis de la facticidad, como en un comienzo se habría podido admitir. Un ejemplo de ello se encuentra en Gerog Jellinek. A primera vista parecería que, en nombre de su "teoría de las dos facetas", Jellinek hubiese querido entender la faceta jurídica como irreductiblemente normativa ${ }^{33}$. Sin

${ }^{28}$ Algunas indicaciones sobre la posición de Kelsen en relación con estos autores se encuentran en: Stanley L. Paulson, "Läßt sich die Reine Rechtslehre transzendental begründen?", en Rechtstheorie 21, 1990, p. 155-179, especialmente p. 159 y ss. (Tiene traducción al español en: Stanley L. Paulson, “¿Es posible la fundamentación trascendental de la teoría pura del derecho?”, en Id., Fundamentación crítica..., op. cit., p. 77-132, especialmente las p. 86 y ss.)

${ }^{29}$ Sobre Austin Cfr. lo referido en la nota núm. 25; sobre Somló, Cfr. su Juristische Grundlehre, 2a . Edición, 1927, reimpresa en 1973, p. 93- 120.

${ }^{30} \mathrm{Cfr}$. En general sobre este aspecto: Stanley L. Paulson, "Läßt sich die Reine Rechtslehre transzendental begründen?”, citado en la nota núm. 28, p. 161 y ss. Tiene traducción al español en: Stanley L. Paulson, “¿Es posible la fundamentación trascendental de la teoría pura del derecho?", citado en la nota núm. 28, p. 89 y ss.).

${ }^{31}$ Rudolf Stammler, Wirtschaft und Recht nach der materialistischen Geschichtsauffassung, 2a. Edición, 1906, p. 180-183, 4a. Edición, 1921, p. 174-177.

${ }^{32}$ Hans Kelsen, Hauptprobleme, citado en nota núm. 3, p. 57-63.

${ }^{33}$ Cfr. Georg Jellinek, System der subjektiven öffentlichen Rechte (citado en la nota núm. 23), p. 12-41; Georg Jellinek, Allgemeine Staatslehre, 2a Edición, 1905, p. 71 y ss., 130-134; 3a. Edición, 1914, p. 74, 136-140 (Tiene traducción al castellano: Teoría General del Estado, 
embargo, a mi modo de ver, Kelsen estima de manera totalmente acertada que, con arreglo a la concepción de Jellinek, en definitiva las normas jurídicas no podrían "ser nada distinto a reglas del ser, que se reflejan como deber ser -psicológicamente- en la conciencia subjetiva de quien debe comportarse de acuerdo con las reglas del derecho". En razón de "esta esencia de las normas jurídicas, acuñada desde una perspectiva fundamentalmente psicologicista" ${ }^{34}$, la teoría de Jellinek hace patente un empirismo radical.

La forma en que Kelsen entiende e interpreta las teorías jurídicas que en aquél entonces estaban en boga, ilustra aquello de lo que trata este primer apartado: el decidido rechazo de Kelsen -expresado con frecuencia con ironía y fundamentado en la distinción entre hecho y valor- hacia todas las supuestas teorías jurídicas basadas en los hechos, preparó el camino a su alternativa a la tesis de la facticidad, es decir, la tesis débil de la normatividad, que se opone de forma contradictoria a la tesis de la facticidad.

No obstante, cabe resaltar que la compresión de Kelsen sobre la distinción entre hecho y valor va mucho más allá de la formulación de esta doctrina que se encuentra en la obra de Simmel o de Hume, o sea, como un sofisma consistente en derivar un deber ser a partir de un ser. Kelsen permite que la principal diferenciación entre ambas formas de pensamiento aparezca con claridad: "ser y deber ser aparecen como dos mundos separados"35. De este modo llegamos a la doctrina de los dos mundos. En el próximo apartado me limitaré a exponer sucintamente la antinomia que se origina a partir de la teoría de los dos mundos, tal como Kelsen la entiende.

\section{La antinomia que se deriva de la doctrina de los dos mundos}

Kelsen introduce la doctrina de los dos mundos, en la que se refiere al "abismo insalvable" que existe entre ambos mundos, el exterior y el normativo (o de la validez).

"El antagonismo entre el ser y el deber ser es de tipo lógico-formal y, en la medida en que no se rebasan los límites de una consideración lógico-formal, ninguno de los dos caminos lleva al otro, los dos mundos permanecen frente a frente el uno del otro, separados por un abismo insalvable." 36

Comares, Granada, 2000). Cfr. En general sobre este aspecto: Hans-Joachim Koch, "Die staatsrechtliche Methode im Streit um die Zwei-Seiten-Theorie des Staates (Jellinek, Kelsen, Heller), en Georg Jellinek. Beiträge zu Leben und Werk, Edt. Por Stanley Paulson y Martin Schulte, 2000, p. 371-389.

${ }^{34}$ Hans Kelsen, Der Soziologische und der juristische Staatsbegriff (citado en la nota núm 22), § 20 (p. 119). (El énfasis aparece en el original).

${ }^{35}$ Hans Kelsen, Hauptprobleme, (citado en la nota núm. 3), p. 8 (el énfasis es mío).

${ }^{36}$ Ibíd. Cfr. También Hans Kelsen, Über Grenzen zwischen juristischer und soziologischer Methode, 1911, p. 6, reimpreso en: Die Wiener rechtstheoretische Schule, Edt. Por Hans Kleca- 
Si sólo existieran pasajes como este, se podría caer en la tentación de entender la "doctrina de los dos mundos" y su discurso del "abismo insalvable" únicamente como una metáfora. Sin embargo, Kelsen se toma en serio esta teoría de los dos mundos. El abismo insalvable de que habla, conduce a una antinomia. Kelsen acepta sin más que "el hombre, que es un objeto de conocimiento bien diverso al del derecho, es decir, el hombre de la biología y de la psicología, en realidad no se sitúa frente al derecho en una relación apropiada para que la ciencia del derecho pueda comprenderlo"37. Con ello se origina una "antinomia inevitable", que Kelsen expone de una manera señaladamente abierta en su "Teoría general del Estado", una de las principales obras de su fase intermedia clásica. Por una parte, el teórico del derecho debe reconocer "la relación material entre los dos [...] sistemas", el de los valores y el de la realidad ${ }^{38}$. La relación interna entre estos dos sistemas se puede caracterizar especialmente con ayuda de la obligación jurídica, porque una obligación jurídica "no puede tener como contenido nada distinto a un comportamiento humano". ${ }^{39}$ Por otra parte, el teórico del Derecho que el dualismo metodológico presupondría necesariamente -según Kelsen-, también debe aceptar que no puede establecerse ninguna relación entre los dos sistemas. ${ }^{40}$ Esta negación de toda posibilidad de establecer relaciones entre los dos sistemas se sigue directamente de la distinción entre hecho y valor, tal como Kelsen la entiende, y refleja la antinomia, en el sentido de que al interior de la filosofía del derecho de Kelsen no puede haber ninguna relación entre el hombre y la persona jurídica, entendida como centro de imputación de las normas. ${ }^{41}$

tsky et alt., 1968, dos volúmenes, (en lo sucesivo: WS 1 y WS 2), tomo 1, p. 3-36, especialmente la p. 6. Hans Kelsen, Allgemeine Staatslehre, (citado en la nota núm. 21), § 13(b) (P. 62). Cfr. En general, sobre este aspecto: Stanley L. Paulson, "Konstruktivismus, Methodendualismus und Zurechnung im Frühwerk Hans Kelsens“, in: Archiv des öffentlichen Rechts, 124 (1999), 631-657, en especial, las p. 640 y ss., y 653. (Tiene traducción al castellano en: Stanley L. Paulson, "Constructivismo, dualismo metódico e imputación en la obra inicial de Hans Kelsen", en Id., Fundamentación crítica de la doctrina de Hans Kelsen, Traducción de Luis Villar Borda, Universidad Externado de Colombia, Bogotá, 2000, en especial las p. 36 y ss, y 66 y 67.)

${ }^{37}$ Kelsen, Allgemeine Staatslehre, (citado en la nota núm. 21) § 13(b) (p. 62); Cfr. También Hans Kelsen, Hauptprobleme (citado en la nota núm. 3), 2ª Edición con nuevo prefacio, 1923, p. XX.

${ }^{38}$ Hans Kelsen, Allgemeine Staatslehre (citado en la nota núm. 21), § 5(c), (p. 19).

${ }^{39}$ Kelsen, RR 1, (citado en la nota núm. 7), § 49 (c), (p. 132).

${ }^{40}$ Kelsen, Allgemeine Staatslehre (citado en la nota núm. 21), § 13(b), (p. 62 y ss.).

${ }^{41}$ Un poco más tarde, en la primera edición de la Teoría pura del Derecho (citado en la nota núm. 7), § 25 (a), (p. 53) Kelsen habla de una "correspondencia" entre el hombre y la persona jurídica, en cuanto centro de imputación jurídica. Sin embargo, en los escritos de Kelsen queda sin explicitarse la manera en que hay que entender esa correspondencia. 
¿Puede resolverse esta antinomia? Para poder responder esta pregunta, -como ya se señaló en la Introducción- es necesario investigar en las fuentes neokantianas de Kelsen. En primer lugar aparece la pregunta de ¿a qué escuela de neokantismo se debe adscribir a Kelsen?

\section{Hans Kelsen como neokantiano}

A pesar de que no se haya estudiado este campo con profundidad, hasta hoy ha prevalecido el convencimiento de que Kelsen habría sido partidario del neokantismo de la escuela de Marburgo, o, en otros términos, que se habría dejado influir a fondo por las doctrinas pregonadas por esta escuela ${ }^{42}$.

Esto es más que descaminado. La máxima influencia del neokantismo en Kelsen fue la del neokantismo sur occidental o de la escuela del Baden. A continuación me detendré en algunos aspectos que sacan a la luz esta influencia. Sin embargo, de antemano vale la pena incursionar brevemente en el interrogante de cómo Kelsen se catalogaba a sí mismo en relación con su propia filosofía. Esto debe hacerse, pues en realidad Kelsen en una cita dio pié a la suposición de que tenía una gran deuda con la escuela de Marburgo, sobre todo con quien era la cabeza de dicha escuela: Hermann Cohen, y quienes defienden la tesis de que Kelsen era un neokantiano acuñado al estilo de la escuela de Marburgo, atribuyen, por razones evidentes, mucho valor a esta cita. Con todo, cuando se pregunta por la catalogación que Kelsen hacía de su propia filosofía, se pone en evidencia que él también se expresa como si quisiese adherirse a la escuela del sur occidente de Alemania o escuela del Baden:

\footnotetext{
${ }^{42}$ Cfr. Sobre la numerosa cantidad de intérpretes que defienden esta concepción en: Eggert Winter, Ethik und Rechtswissenschaft, 1980, p. 34, nota 102. A ellos deberían sumarse: Karl Larenz, Rechts- und Staatsphilosophie der Gegenwart, 1ª Edición, 1931, p. 31; Renato Treves, "Il fondamento filosofico della doctrina pura del diritto di Hans Kelsen", in Atti della Reale Academia delle Scienze di Torino 69, 1933/34, p. 52-90, especialmente las p. 62-78, reimpreso en: Hans Kelsen und Id., Formalismo giuridico e realtà sociale, Edt. por Stanley L. Paulson, 1992, p. 59-87, especialmente las p. 66-78; finalmente el libro de William Ebenstein aparecido en Praga: Die rechtsphilosophische Schule der Reinen Rechtslehre, 1938, reimpreso en 1969, p. 43, 86. Las nuevas investigaciones sobre el problema de cuál fue el papel que jugó la escuela de Marburgo en la teoría jurídica de Kelsen, son mucho más sutiles, cfr. no sólo Eggert Winter (la cita de esta nota), p. 33-38, sino también Helmut Holzhey, "Kelsen Rechts- und Staatslehre in ihrem Verhältnis zum Neukantianismus", en: Untersuchungen zur Reinen Rechtslehre, Edt. por Stanley Paulson y Robert Walter, 1986, p. 167-192, y Geert Edel, "The Hipothesis of the Basic Norm: Hans Kelsen und Hermann Cohen”, en Normativity and Norms (cita 1), p. 195-219. Existe una versión alemana reducida, bajo el título: "Zum Problem der Rechtsgeltung. Kelsens Lehre von der Grundnorm und das Hipótesis-Theorem Cohens", en Grenzen der kritischen Vernunft. Helmut Holzhey zum 60. Geburtstag, Edt. por Peter A. Schmid y Simone Zurbuchen, 1997, p. $178-194$
} 
"En los "Problemas Capitales" se trata en primer lugar de obtener la particularidad del derecho frente a la naturaleza o frente a la realidad social determinada de la misma forma en que se determina la naturaleza.

Por ello los "Problemas Capitales" parten de la contraposición fundamental entre el deber ser y el ser, descubierta primero por Kant, en su intento por fundamentar la autonomía de la razón práctica frente a la razón teórica, la autonomía de los valores frente a la realidad, de la moral frente a la naturaleza. En conexión con la interpretación de Kant que hacen Windelband y Simmel, el deber ser se convierte para mí en la expresión de la particularidad del derecho que debe determinarse por la ciencia jurídica, y que debe diferenciarse de un ser social concebido desde un punto de vista "sociológico"..."43

Sin embargo, tres observaciones resultan mucho más importantes que las propias formulaciones de Kelsen -en esta cita a favor de la escuela del Baden, pero en otras citas, que curiosamente se encuentran en la misma obra, a favor de la escuela de Marburgo $0^{44}$, y en una obra publicada dos años más tarde, a favor de la filosofía de $\mathrm{Kant}^{45}$-: en primer lugar, que desde el comienzo Kelsen adoptó algunas doctrinas fundamentales de la escuela del Baden; segundo, que además, en algunos pasajes decisivos, su terminología refleja inequívocamente aquélla de la escuela del Baden; $y$, tercero, que él conocía bien algunos de los trabajos de los neokantianos de la escuela del Baden. Algo similar no puede decirse sobre Kelsen y la escuela de Marburgo. A continuación profundizaré en estos tres puntos. Luego regresaré otra vez sobre el tema de la escuela de Marburgo.

\section{1. Doctrinas}

Entre las doctrinas de los neokantianos del Baden que Kelsen adoptó, se destaca sobre todo la propia doctrina de los dos mundos, o dicho con mayor precisión, la investigación de Wilhelm Windelband sobre los puntos de vista explicativo y normativo, y la investigación

\footnotetext{
${ }^{43}$ Hans Kelsen, Hauptprobleme (citado en la nota núm. 3), 2a . Edición con nuevo prólogo, 1923 , p. VI (el énfasis aparece en el original).

${ }^{44} \mathrm{C}$ fr. Texto citado en la nota núm. 88.

${ }^{45}$ El método de la teoría del Estado positivo "está -más o menos conscientemente, más o menos consecuentemente- determinado por medio de la crítica kantiana a la razón: dualismo entre ser y deber ser; reemplazo de los postulados metafísicos y de las hipóstasis mediante categorías trascendentales como las condiciones de la experiencia; transformación de las antinomias absolutas -en cuanto cualitativas y transsistemáticas- dentro de una misma disciplina, en diferencias relativas, cuantitativas e intrasistemáticas; ascenso a la esfera subjetiva del psicologismo en el ámbito de la validez lógico-objetiva: estos son algunos de los momentos esenciales de este método. Y éstas son las directivas decisivas de mi trabajo teórico jurídico”, Hans Kelsen, Allgemeine Staatslehre (citado en la nota núm. 21), prólogo, p. VII.
} 
correlativa, desarrollada por Heinrich Rickert, sobre los "reinos" o mundos. Es por esto que la diferencia entre el punto de vista explicativo y normativo, que Kelsen tomó de los "Preludios" de Windelband, cimienta la tesis de los dos mundos que aparece en algunos pasajes de su obra. Esta doctrina del neokantismo de la escuela del Baden es sin duda fundamental para la filosofía del derecho de Kelsen. Esta doctrina subyace a la tesis débil de la normatividad, que sin ella es inimaginable.

En el artículo de Windelband "Normen und Naturgesetze" (Normas y leyes de la naturaleza), aparecido en los "Preludios" $(1884)^{46}$, este autor comienza con la presentación de un esquema variopinto del dilema central de la filosofía:

“¿Puedo hacer, aquello que debo hacer? - - esta es la pregunta! Siento una fuerza en mí, de tal modo que, como la ley de la gravedad determina a la piedra, así se configura necesaria e inevitablemente mi idea, mi deseo, mi sentimiento: y aparece en mí la conciencia de un mandato, y según dicha conciencia debo pensar, querer, sentir. ¿Cómo se comportan entre sí aquella fuerza y este mandato,-de qué manera son compatibles y qué sentido tiene el hecho de que se encuentren el uno al lado del otro? Si todo debe suceder en mí tal como de hecho sucede, ¿qué sentido tiene un mandato? ¿Ordena acaso lo mismo, como toda coacción? Y en ese caso, ¿para qué entonces exigir aquello que por sí mismo sucede? Si por el contrario, ordena otra cosa, ¿que sentido tiene entonces exigir algo que no puede suceder?" ${ }^{47}$

Windelband alude a la impresión de que se está frente a un dilema, refiriendo que en ambos lados se encuentran variantes inaceptables - su alusión al "axioma científico" es en este contexto una abreviación de que las leyes de la naturaleza serían por sí mismas suficientes para fundamentar que todo en mí tiene que suceder como de hecho sucede-. La alternativa es atenerse al axioma científico, sin poder reconocer la validez del mandato, o al contrario: reconocer el mandato y el "patrimonio de la libertad correlativo a éste", pero al mismo tiempo poner en tela de juicio "la validez del axioma científico" ${ }^{48}$. En realidad, este dilema se presenta en los tres ámbitos de la filosofía que se consideran a continuación: la ética, la lógica y la estética ${ }^{49}$.

\footnotetext{
${ }^{46}$ Wilhelm Windelband, "Normen und Naturgesetze", en: Präludien, 1a. Edición, 1884, p. 211-246, 9a. Edición, 1924, tomo II, p. 59-98. El artículo ya aparecía en la primera edición de los Preludios. Windelband lo aceptó con algunas variaciones y adiciones en la tercera edición, y en esta forma se reprodujo en las ediciones posteriores. Mi cita del artículo se refiere a la versión que aparece en la primera edición de los Preludios, que en mi opinión refleja la versión original del texto leída por Kelsen.

${ }^{47}$ Ibíd., $1^{a}$ Edición, p. 211, 9a Edición, Tomo II, p. 59.

${ }^{48}$ Ibíd., $1^{\text {a }}$ Edición, p. 214, $9^{\text {a }}$ Edición, Tomo II, p. 62.

${ }^{49}$ Ibíd., $1^{\text {a }}$ Edición, p. 217, $9^{\text {a }}$ Edición, Tomo II, p. 65.
} 
Para solucionar el dilema, Windelband procede de una manera decididamente kantiana ${ }^{50}$, en la que diferencia entre dos puntos de vista: uno explicativo o propio de las leyes de la naturaleza y otro normativo. Como ejemplo del último puede servir una ley del pensamiento propuesta por la lógica; esta ley expone una determinada forma de conexión entre los elementos del razonamiento, según la cual, "en el individuo pueden producirse ciertas condiciones, pero también pueden estar ausentes" $" 51$. En realidad, todas aquellas leyes, es decir, aquellas de la lógica, de la ética y de la estética, serían formas especiales de realización de las leyes de la naturaleza. "El sistema de las normas representa una gama de la insoslayable diversidad de las formas de combinaciones en las que las leyes de la naturaleza de la vida física se pueden configurar, según sean los comportamientos individuales" 52 . Según Windelband, tan pronto se reconoce que las normas deben verse de este modo, es decir, como determinadas formas de realización de las leyes de la naturaleza, se soluciona el dilema filosófico por sí mismo. Aquello que sucede necesariamente por la naturaleza, se enjuicia según las "normas ideales" El punto de vista normativo "del pensamiento lógico, ético y estético no exige ni que suceda lo que siempre sucede de esa manera exacta, ni aquello que de ningún modo puede suceder: sino que autoriza a hacer algunas cosas de aquellas que pueden suceder, para rechazar las restantes" ${ }^{\prime 4}$.

El problema de si la solución que Windelband propone para el dilema filosófico es sostenible, puede dejarse de momento sin decidir. Ello, porque lo que para mis fines es interesante en esa doctrina ${ }^{55}$, es si ella se encuentra

${ }^{50}$ Ello, sin aludir a Kant, porque Windelband cree que también Kant se encuentra frente a ese dilema, cfr. Ibíd., $1^{\text {a }}$ Edición, p. 214, $9^{\text {a }}$ Edición, Tomo II, p. 62.

${ }^{51}$ Ibíd., $1^{\text {a }}$ Edición, p. 217, 9ª Edición, Tomo II, p. 65.

${ }^{52}$ Ibíd., $1^{\text {a }}$ Edición, p. 224 y ss. (el énfasis aparece en el original), $9^{\text {a }}$ Edición, Tomo II, p. 72 y ss.

${ }^{53}$ Ibíd., $1^{\text {a }}$ Edición, p. 219, $9^{\text {a }}$ Edición, Tomo II, p. 67.

${ }^{54}$ Ibíd., $1^{\text {a }}$ Edición, p. 226, $9^{\text {a }}$ Edición, Tomo II, p. 74.

${ }^{55}$ ¿Se encuentra en los escritos de Kelsen una doctrina de la libertad comparable con ésta? Esta pregunta debe responderse afirmativamente. Aquí es relevante la segunda esfera normativa de Kelsen, en la que el hombre "de la biología y de la psicología" se reemplaza por una persona jurídica consistente en un centro de imputación. Hans Kelsen, Allgemeine Staatslehre, (citado en la nota núm. 21), § 13 (b), p. 62, pasaje citado en la nota 37 del texto. Kelsen escribe: "Si se entiende por "voluntad" - cuya la libertad se afirma tendencialmente desde hace mucho tiempo-el acto que se desarrolla en el ámbito de lo real y físico, es decir, en el ámbito de la naturaleza determinada por el principio de causalidad, entonces conceptualmente no se puede hablar en realidad de libertad. Comenzar a considerar la conducta - como efecto de una causa- como el acto de voluntad como causa primera, contradice el sentido en que se presupone la categoría de la causa y el efecto. Si la expresión "libertad de la voluntad" debe tener un sentido posible, entonces la "voluntad" no puede aceptarse como un hecho real y físico (porque en ese caso ya se ha aceptado que está determinada causalmente) entonces el concepto de voluntad debe entenderse en el sentido normativo en el que se aquí se ha señalado reiteradamente. El querer, cuya libertad es 
de nuevo en Kelsen. Con una referencia al artículo de Windelband, que antes he citado, Kelsen aclara ya al comienzo de los "Problemas capitales" que él adoptó la diferenciación de Windelband entre la perspectiva explicativa y la normativa:

"Habitualmente las leyes de la naturaleza, que explican lo que existe realmente, se entienden como normas que se contraponen a todos los demás tipos de leyes que estatuyen un deber ser, tales como las leyes consuetudinarias, jurídicas, lógicas, gramáticas y estéticas (...). Esta contraposición, que tiene un inmenso significado para el método de las disciplinas normativas y especialmente para la ciencia del derecho, se basa en una diferencia del punto de vista desde el cual el hombre observa los objetos. Mientras el cometido de las ciencias naturales es explicar y mostrar el comportamiento real de las cosas, es decir, comprender el ser, otras disciplinas establecen reglas que prescriben comportamientos, que exigen un ser o un no ser, o sea, que estatuyen un deber ser. El primer punto de vista se conoce como el punto de vista explicativo y el último como el normativo, y las reglas que estatuyen un deber ser se llaman reglas, al paso que las reglas del ser tienen validez como leyes de la naturaleza en el sentido más amplio"56.

posible, es el deber ser, y la "persona" que puede ser libre, no es el hombre sino el orden del deber ser personificado. En la aceptación de la libertad de la persona radica en primer lugar y de forma puramente negativa, el rechazo de la determinación de la conducta por leyes causales, como una normatividad totalmente ajena al ámbito del deber ser”. Ibíd., § 15 (b) (p. 71 y ss.).

Además de lo anterior, debería investigarse si la doctrina de la libertad de Kelsen pone en duda su propia valoración de la filosofía práctica kantiana. Como quiera que esta doctrina de Kelsen, pasando por Windelband, puede reconducirse a Kant, de cuya doctrina es a la vez reflejo, parece ser difícil hacer compatible el apoyo de Kelsen hacia esta doctrina, con sus observaciones poco encomiosas sobre la filosofía práctica de Kant. De acuerdo con Kelsen, la "Metafísica de las costumbres" de Kant, podría "considerarse como la expresión más completa de la teoría clásica del derecho natural, tal como se desarrolló durante los Siglos XVII y XVIII sobre la base del cristianismo protestante". Emanciparse totalmente de la metafísica de la filosofía práctica de una "personalidad tan profunda y arraigada en el cristianismo" como Kant, habría sido imposible. Es por ello que "Kant, cuya filosofía trascendental está llamada especialmente a ofrecer un fundamento a la teoría del derecho positivo y del Estado, en cuanto filosofía del derecho se quedó en los caminos trillados de la doctrina del derecho natural". Hans Kelsen, "Die philosophischen Grundlagen der Naturrechtslehre und des Rechtspositivismus" (1928), § 40 (p. 76) (el énfasis aparece en el original), reimpreso en: WS 1 (citado en la nota núm. 36), p. 281-350 (p. 349). Cfr. También: Hans Kelsen, Wesen und Wert der Demokratie, 2. Edición, 1929, p. 119, nota 45: "El sistema ético-político de Kant está totalmente orientado hacia la metafísica y su filosofía práctica se identifica con los valores absolutos del Estado y de la teoría jurídica conservadores y monárquicos"; Hans Kelsen, "Reine Rechtslehre, "Labandismus" und Neukantianismus. Ein Brief an Renato Treves", en: Id. y Renato Treves, Formalismo giuridico e realtà sociale (citado en la nota núm. 42), p. 55-58, especialmente las p. 56 y ss.; Hans Kelsen, Reine Rechtslehre, 2. Edición, 1960, p. 368-374, especialmente las 388 y ss. (citado en la nota núm 35), p. 420-425.

Es preciso reconocer que la apelación de Kelsen a la doctrina de Kant sobre la libertad, y de su aún más profunda aceptación de una segunda esfera normativa o de la validez junto a la del mundo exterior, presupone la aceptación de algunos elementos esenciales de la filosofía práctica kantiana.

${ }^{56}$ Hans Kelsen, Hauptprobleme (citado en nota núm. 3), p. 4 y ss. (El énfasis es del original), Cfr. También p. 28, 71. Kelsen alude tanto a Windelband, "Normen und Naturgesetze" 
Más allá del ejemplo del derecho, Kelsen no se interesa por las particularidades de la solución de Windelband al dilema filosófico. Sin embargo, en lo que concierne al derecho, Kelsen no puede ser del mismo parecer de Windelband. Esto se debe a que Kelsen supone acertadamente que las normas del derecho sólo tienen sentido, si puede existir una disparidad entre lo que realmente sucede, según las leyes de la naturaleza, y lo que las normas exigen. Si se observa bien, la solución de Windelband excluye la posibilidad de que exista esta disparidad ${ }^{57}$.

En lugar de seguir a Windelband, Kelsen utiliza la doctrina de los dos mundos que va más allá del modelo de aquel autor, que hemos descrito.

"La división entre disciplinas explicativas y normativas, entre las ciencias causales y normativas, se fundamenta en la contraposición entre el ser y el deber ser. Mientras aquellas disciplinas se orientan hacia lo que realmente está dado, el mundo del ser, la realidad, la perspectiva de éstas se refiere al mundo del deber ser, a lo ideal". ${ }^{58}$

Como ya se ha expresado, sería viable tender a observar estas líneas sólo como una metáfora, si no se supiera que el propio Kelsen se planteó expressis verbis la antinomia resultante de la teoría de los dos mundos y sus consecuencias.

En la medida en que Kelsen se apoya en la teoría de los dos mundos, Windelband deja de ser su fundamento filosófico entre los neokantianos de la escuela del Baden; este papel lo asume Heinrich Rickert. Este autor había utilizado dos años antes la misma formulación mediante la cual Kelsen menciona la antinomia resultante de la doctrina de los dos mundos en los "Problemas capitales", publicado en 1911, es decir, que ambos mundos estarían separados entre sí en razón de un "abismo insalvable". Un "abismo insalvable" es el que existe entre el reino de los "valores teóricos" y el de la "realidad empírica"59. En su obra capital "System der Philosophie" (Sistema de la filosofía" (1921) Rickert se ocupa luego con mayor profundidad de la doctrina de los dos mundos. ${ }^{60}$

(citado en la nota núm. 46), como también a Wilhelm Wundt, Ethik, 3ª Edición, 1903, p. 1 y ss. Cfr. También sobre el tema de Kelsen: Wilhelm Wundt, Logik, 2a . Edición, 1893, Tomo 1, p. 1 y ss., 90-93.

${ }^{57}$ Hans Kelsen, Hauptprobleme (citado en nota núm. 3), p. 24 y ss.

${ }^{58}$ Hans Kelsen, "Über Grenzen zwischen juristischer und soziologischer Methode" (citado en la nota núm. 36), p. 10 y ss. (el énfasis es del original); Cfr. También las p. 6 y ss.; Reimpreso en: WS 1 (citado en la nota núm. 36), p. 8 y ss; Cfr. También p. 6 y ss. En la nota núm. 36 ya se citó un pasaje proveniente de los Problemas Capitales, sobre la doctrina de los dos mundos.

${ }^{59}$ Heinrich Rickert, “Zwei Wege der Erkenntnistheorie”, en: Kantstudien 14, 1909, p. 169 228 (especialmente la p. 218), cfr. También las p. 220 y ss.

${ }^{60}$ Cfr. Heinrich Rickert, System der Philosophie, primera parte: Allgemeine Grundlegung der Philosophie, 1921 (en lo sucesivo: System), especialmente el capítulo V: "Das dritte Reich" 
"Todo lo que meramente existe tiene algo en común en comparación con aquello que posee carácter de valor y por ello el mundo se divide en dos esferas bien particularizadas, que, habida cuenta de sus relaciones y conexiones, deben mantenerse estrictamente contrapuestas en lo conceptual, siempre que se pretenda claridad sobre todo lo que existe en el mundo. Los valores ideales se contraponen como reino a todos los objetos realidad, que en todo caso también constituyen un reino en sí mismo". ${ }^{61}$

Al igual que Kelsen, Rickert es consciente de que la relación entre los dos reinos plantea un problema fundamental: ¿cómo se configura esa relación de manera precisa, "de tal forma que el mundo no se desmorone en dos reinos? ${ }^{62 "}$ Con todo, de modo bien contrapuesto a Kelsen, Rickert intenta solucionar este problema apelando al sentido inmanente de los actos mediante los que se adopta una determinada posición frente a los valores. En el aparado 5 se volverá sobre este aspecto.

La diferencia de Windelband entre las dos perspectivas, así como la correlativa doctrina de los dos mundos planteada por Rickert, constituyen una doctrina neokantiana de la escuela del Baden, que como se mencionó anteriormente, también se evidenció como fundamental para la filosofía del derecho de Kelsen. Este es el primero de los tres puntos con fundamento en los cuales puede evaluarse la corrección de la tesis según la cual, Kelsen debería considerarse como un representante de algunas posiciones fundamentales de la escuela neokantiana del Baden. Aún hace falta referirse a dos puntos adicionales: el de la terminología común y el de la familiaridad de Kelsen con los trabajos de los neokantianos de la escuela del Baden.

\subsection{Terminología}

Toda una serie de expresiones características del Kelsen encuentra un correlato en los escritos de los neokantianos del Baden. Tal vez la más llamativa de dichas expresiones fue la frase "realidad y valor" que se halla por todas partes en los escritos de Kelsen durante la fase clásica ${ }^{63}$, y que

(El tercer reino) (p. 233-318); no se publicaron otras partes de la obra. Yo utilizo el "System" de Rickert a causa de su plenitud. Sin embargo, la doctrina de los dos mundos fue expuesta en algunos escritos de Rickert anteriores al "System", como muestra la cita tomada de "Zwei Wege der Erkenntnistheorie" (citado en la nota núm. 59). Cfr. También Heinrich Rickert, "Vom Begriff der Philosophie", en: Logos 1, 1910/11, p. 1-34, especialmente las p. 19, 21 y ss, 26 y ss, reimpreso en: Heinrich Rickert, Philosophische Aufsätze, Edt. Por Rainer A. Bast, 1999 (en adelante: Aufsätze), p. 3-36, especialmente las p. 21, 23 y ss., 28 y ss. En general sobre Rickert: Christian Krijnen, Nachmetaphysischer Sinn. Eine problemgeschichtliche und systematische Studie zu den Principien der Wertphilosophie Heinrich Rickerts, 2001; la detallada monografía de Krijnen puede considerarse como el mejor estudio general sobre Rickert.

${ }^{61}$ Heinrich Rickert, System (citado en la nota núm. 60), p. 114.

${ }^{62}$ Ibíd., p. 235.

${ }^{63}$ Cfr. Sobre las fases de evolución de la filosofía jurídica de Kelsen la nota núm. 3. 
también se encuentra en los escritos de Rickert. Aun cuando se esté dispuesto a contar en el texto las veces que aparece la contraposición de estas dos expresiones en sus diferentes variantes, debe decirse que ella aparece en el System de Rickert literalmente cien veces más ${ }^{64}$. Algunos ejemplos puede evidenciar la similitud en la terminología de ambos pensadores.

La frase estándar "realidad y valor" se encuentra diversamente en los trabajos de Kelsen, muy a menudo de forma paralela a la frase "ser y deber ser" ${ }^{\prime 6}$. Kelsen contrapone la "realidad natural" al "sistema de valores", y paralelamente a ello corre su antagonismo entre "legalidad causal" y "legalidad propia de lo normativo" 66 . En el punto culminante de su fase clásica, Kelsen introdujo su frase tradicional sobre el "conocimiento de la realidad" y el "conocimiento de los valores". ${ }^{67} \mathrm{Y}$ al final de la fase clásica se encuentra la contraposición entre "juicios de realidad" y "juicios de valor"68.

Como ya se ha dicho, Rickert utiliza también la frase estándar "realidad y valor" en numerosas citas $^{69}$. Asimismo se encuentran distintas variantes que incluyen la contraposición entre "lo real" y "los valores"70, así como entre "lo real" y "lo valorativo" "71. También se habla del antagonismo entre "problemas de la realidad" y "problemas de valores"72, así como de "conceptos reales" y "conceptos valorativos"

${ }^{64}$ Por ejemplo, puede echarse una mirada a una cita en que aparece siete veces la contraposición entre variantes de estas dos expresiones: Heinrich Rickert, System (citado en la nota 60), p. 256.

${ }^{65}$ Cfr. Por ejemplo, Hans Kelsen, "Die Rechtswissenschaft als Norm- oder als Kulturwissenschaft", en Schmollers Jahrbuch für Gesetzgebung, Verwaltung und Volkswirtschaft im Deutschen Reiche, núm. 40, 1916, p. 1181-1239, en especial la p. 1182; reimpreso en: WS 1 (citado en la nota 36), p. 37-93, en especial la p. 38; Hans Kelsen, Hauptprobleme (citado en

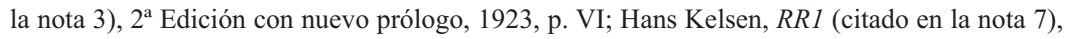
$\S 8$, p. 12 .

${ }^{66}$ Hans Kelsen, Allgemeine Staatslehre (citado en la nota núm. 21), § 4 (d), p. 15.

${ }^{67}$ Hans Kelsen, "Die philosophischen Grundlagen der Naturrechtslehre und des Rechtspositivismus" (citado en la nota núm. 55), § 23, p. 43; reimpreso en: WS 1 (citado en la nota núm. 36), p. 317.

${ }^{68}$ Hans Kelsen, Reine Rechtslehre, $2^{\mathrm{a}}$. Edición (citado en la nota núm. 55), § 4 (e), p. 17; Cfr. También Hans Kelsen, "Value Judgments in the Science of Law", en: Journal of Social Philosophy and Jurisprudence núm. 7, 1942, p. 312-333; reimpreso en Hans Kelsen, What is Justice? (citado en la nota núm. 25), p. 209-230.

${ }^{69}$ Cfr. Heinrich Rickert, "Zwei Wege der Erkenntnistheorie" (citado en la nota núm. 59), p. 218, 220, 222, 224; Heinrich Rickert, "Vom Begriff der Philosophie" (citado en la nota núm. 60), p. 11-13, 15-17, 19-25, 27, 29, 31, 33; reimpreso en Heinrich Rickert, Aufsätze (citado en la nota núm. 60), p. 13-15, 17-19, 21-27, 29, 31, 33, 35; Heinrich Rickert, System (citado en la nota núm. 60), p. 116, 123, 128, 138, 141 y ss., 148, 158, 160, 168, 220, 232, 234, 254, 291, 297, 305, etc.

${ }^{70}$ Cfr. Ibíd., p. 181, 192, 233, 258 y 282, etc.

${ }^{71}$ Cfr. Ibíd., p. 138, 255.

${ }^{72}$ Cfr. Ibíd., p. 127, 136, 148, 149, 176, etc.

${ }^{73}$ Cfr. Ibíd., p. 133. 
de lo real" que se contrapone a la "ciencia de los valores" 74 . También entra en escena el antagonismo entre "los niveles de realidad" y "los niveles de valores"75, y muy próximos a ellos, lo que está "sobre la realidad" y "sobre los valores"76. Otra variante más es la contraposición entre el "todo de la realidad" y el "todo de los valores" 77 . A diferencia de Kelsen, Rickert no contrapone inmediatamente la expresión "conocimiento de la realidad" al correlato de "conocimiento de los valores", sino que utiliza la expresión "conocimiento de la realidad" en oposición a la "filosofía del conocimiento" y entiende por ella una "teoría de los valores teoréticos"78.

Esta similitud terminológica no se presenta por casualidad. Ambos pensadores son tributarios de la doctrina de los dos mundos y la frase "realidad y valor", así como sus variantes, se refieren a dicha doctrina. Sin embargo, es interesante observar que esta similitud entre los dos pensadores va más allá de la apelación a la doctrina de los dos mundos y se convierte en un lenguaje común.

Es posible traer a colación otras expresiones características de Kelsen, como correlato de expresiones que se encuentran en los escritos de los neokantianos del Baden, sobre todo en los de Rickert. Sin embargo, la síntesis expuesta es suficiente para mis fines. Con ello puedo pasar al tercer punto.

\subsection{Familiaridad}

En el tercer punto se trata de que Kelsen conoció muy bien algunos trabajos de los neokantianos del Baden. Como ya se mencionó, en los Problemas Capitales partió de la diferencia entre los puntos de vista aclarativo y normativo de Windelband. En este contexto, Kelsen tuvo la oportunidad de ocuparse del artículo de Windelband "Normen und Naturgesetze" (normas y leyes de la naturaleza). Cinco años después discutió detalladamente con Emil Lask, Gustav Radbruch y sobre todo con Rickert ${ }^{79}$. Profundizó en la obra de Rickert "Kulturwissenschaft und Naturwissenschaft" (ciencia de la cultura y ciencia de la naturaleza), se ocupó de la filosofía del derecho de Lask y dio cabida en la discusión a los "Fundamentos de filosofía del derecho" de Radbruch ${ }^{80}$. Es indiscutible que Radbruch se dejó in-

${ }^{74}$ Cfr. Ibíd., p. 135.

${ }^{75}$ Cfr. Ibíd., p. 137.

${ }^{76}$ Cfr. Ibíd., p. 138.

${ }^{77}$ Cfr. Ibíd., p. 164.

${ }^{78}$ Cfr. Ibíd., p. 177-179, 257.

${ }^{79}$ Cfr. Hans Kelsen, "Die Rechtswissenschaft als Norm- oder als Kulturwissenschaft" (citado en la nota núm. 65).

${ }^{80}$ Heinrich Rickert, Kulturwissenschaft und Naturwissenschaft, 3a. Edición, 1915; Emil Lask, "Rechtsphilosophie", en: Die Philosophie im Beginn des zwanzigsten Jahrhunderts. 
fluenciar profundamente por los neokantianos del Baden. Aunque a primera vista podría parecer que Kelsen, en su discusión, hubiese querido rechazar totalmente la teoría de Radbruch, en realidad adoptó sub silentio más de ella que lo que permite suponer expressis verbis su rechazo explícito. ${ }^{81}$ Seis años después de esta álgida discusión, Kelsen retornó a Lask en su trabajo "Rechtswissenschaft und Recht" (ciencia del derecho y derecho) ${ }^{82}$. Esta vez se trata del trabajo de Lask sobre la doctrina de las categorías ${ }^{83}$. Incluso en la última fase escéptica de Kelsen ${ }^{84}$-la obra principal publicada póstumamente Teoría de las normas contiene numerosas, y en parte, bien valiosas referencias al respecto- aparece un neokantiano del Baden: Rickert. ${ }^{85}$ Por medio de Rickert, Kelsen conoció muy bien los trabajos de un teórico: Georg Simmel, cuyo pensamiento evidencia en cierta medida un parentesco con los neokantianos del Baden. ${ }^{86}$

No se puede afirmar que el conocimiento que Kelsen tenía de los trabajos de los neokantianos del Baden fuese especialmente profuso. Sin embargo, en comparación con la prueba un tanto insuficiente de los conocimientos que tenía de los escritos de la escuela de Margurbo, puede decirse que en este ámbito Kelsen era en realidad un entendido.

Kelsen y la escuela de Marburgo. Resulta muy común la referencia a la escuela de Marburgo y sobre todo al emblemático Hermann Cohen, cuando se pregunta por las fuentes neokantianas de algunos conceptos y doctrinas de Kelsen ${ }^{87}$. A primera vista parece muy promisorio de ello el pasaje correspondiente que aparece en el prólogo a la segunda edición de sus "Problemas Capitales" - un pasaje al que los defensores de la tesis de que Kelsen era un neokantiano de la estirpe de Margurbo, atribuyen mucho valor.

Festschrift für Kuno Fischer, Edt. por Wilhelm Windelband, 2a. Edición, 1907, p. 269-320; Gustav Radbruch, Grundzüge der Rechtsphilosophie, 1914; reimpreso en: Id., Gesamtausgabe, Tomo 2 (citado en la nota núm. 16), p. 9-204, 509-561.

${ }^{81}$ En general con ello se trata de la conservación por parte de Kelsen del concepto filosófico de validez de los neokantianos de la escuela del Baden.

${ }^{82}$ Hans Kelsen, "Rechtswissenschaft und Recht", en Fritz Sander/Hans Kelsen, Die Rolle des Neukantianismus in der Reinen Rechtslehre, Edt. por Stanley L. Paulson, 1988 (en lo sucesivo: Die Rolle des Neukantianismus), p. 249-411, especialmente las p. 365 a 370.

${ }^{83}$ Emil Lask, Die Logik der Philosophie und die Kategorienlehre, 1911.

${ }^{84} \mathrm{Cfr}$. Sobre la última fase de desarrollo de la filosofía del derecho de Kelsen: la nota núm. 3.

${ }^{85}$ Cfr. Hans Kelsen, Allgemeine Theorie der Normen, Edt. por Kart Ringhofer/Robert Walter, 1979, p. 221, nota 1, p. 296, nota 118.

${ }^{86}$ En lo que concierne a Simmel como neokantiano, Cfr. A. M. Bevers, Dynamik der Formen bei Georg Simmel, 1985, especialmente las p. 31-71.

${ }^{87} \mathrm{Cfr}$. Las referencias mencionadas en la nota núm. 42. 
"De la interpretación de Cohen sobre la doctrina de Kant, sobre todo en su "Ética de la voluntad pura", obtuve el punto de vista decisivo sobre teoría del conocimiento, que me fue imprescindible para llegar a una concepción correcta del Estado y del Derecho. Una recensión de mis "Problemas capitales de la teoría del Estado", publicada en 1912 en los Kantstudien, en la que se consideraba a esta obra como un intento de aplicar el método trascendental a la ciencia jurídica, me llamó la atención sobre el paralelismo considerable que existía entre mi concepto de voluntad jurídica y los razonamientos de Cohen, que hasta entonces no me eran conocidos. A partir de ese momento se me suscito entonces la conciencia de la concepción fundamental que Cohen tenía sobre la teoría del conocimiento. De acuerdo con esta concepción, la dirección del conocimiento determina el objeto del mismo; el objeto de conocimiento se produce lógicamente a partir de una fuente. El Estado, entonces, en cuanto constituye objeto del conocimiento jurídico, sólo puede ser derecho, porque conocer o entender algo desde el punto de vista jurídico no significa otra cosa que concebirlo como derecho." 88

En esta cita, Kelsen alude a los siguientes conceptos: (1) el método trascendental, (2) el concepto de voluntad jurídica y luego a las doctrinas específicas del "conocimiento teorético", (3) a la determinación del objeto de conocimiento mediante la dirección o el método del conocimiento, y (4) a la producción lógica del objeto del conocimiento a partir de cierto origen, y finalmente, (5) a la identidad entre Estado y Derecho. A continuación quisiera referirme a todos estos objetos.

El primer objeto en la enumeración de Kelsen, el método trascendental, no remite directamente al asunto de la influencia de los neokantianos de Marburgo. Kelsen ya había aplicado el método trascendental en los Problema Capitales -así lo indica la afirmación de Oscar Ewald, el autor de la recensión en los Kantstudien, de la que Kelsen habla en el pasaje del prólogo antes citado. ${ }^{89}$ La afirmación de Ewald no puede sustentarse en demasiadas evidencias, pero, a pesar de ello, la pregunta sobre la influencia de la escuela de Marburgo en los trabajos tardíos de Kelsen no deja de tener interés. Desde luego no puede excluirse que los neokantianos de Marburgo hubiesen influido en Kelsen, en lo referente a la aplicación del método trascendental, en trabajos posteriores a los Problemas Capitales. Es sabido que, ante todo Cohen expuso elegantemente el método trascendental en más de una obra temprana ${ }^{90}$, y que el artículo de Paul Natorps "Kant und die Marburger

${ }^{88}$ Hans Kelsen, Hauptprobleme (nota 3), 2a . Edición con nuevo prólogo, 1923, p. XVII.

${ }^{89}$ Ibid. Cfr. Oscar Ewald, "Die deutsche Philosophie im Jahre 1911”, en: Kantstudien, núm. 17, 1912, p. 382-433, especialmente las p. 396-398.

${ }^{90}$ Cfr. Por ejemplo, Hermann Cohen, Kants Begründung der Ethik, $1^{\mathrm{a}}$. Edición, 1877, p. 24 y ss.; Hermann Cohen, Das Prinzip der Infinitesimal-Methode und seine Geschichte, 1883, reimpreso con una introducción de Meter Schulthess, 1984, p. 5; Hermann Cohen, Kants Theorie der Erfahrung, 2a. Edición, 1885, p. 77. Cfr. En general sobre el método trascendencial: Geert Edel, Von der Vernunftkritik zur Erkenntnislogik, 1988, p. 117-125; Jürgen Stolzenberg, Urs- 
Schule" (Kant y la escuela de Marburgo) ${ }^{91}$ ofrece tal vez la exposición más accesible del método trascendental que se conozca. No obstante, naturalmente la influencia de la escuela de Marburgo no excluye la influencia de la escuela de los neokantianos del Baden. Dado que, como ya se mostró, algunas de las obras de los neokantianos del Baden eran bien conocidas por Kelsen, puede admitirse que su referencia al método trascendental -en el caso Rickert frecuentemente en citas de paso, relacionadas con el concepto de "suposición"92 - también era conocida por Kelsen".

Tampoco el concepto de voluntad jurídica, el segundo objeto de la enumeración de Kelsen, remite directamente a la influencia de los neokantianos de Marburgo, porque este autor ya había trabajado plenamente este concepto en los Problemas Capitales ${ }^{94}$, es decir, en un momento en que desconocía por entero la filosofía de Cohen. Las verdaderas preguntas que plantea la enumeración de Kelsen, surgen de las doctrinas específicas del "conocimiento teórico", a saber, las (3) y (4), así como la (5), o sea la tesis acerca de la identidad entre Estado y Derecho. Comenzaré con el punto (3), es

prung und System, 1995, p. 30-34. En un escrito muy temprano: Kants Theorie der Erfahrung, $1^{\text {a }}$. Edición, 1871, reimpresa en 1987, p. 206, Cohen compara expressis verbis el método trascendental con la forma de enseñar regresiva de Kant; Cfr. Sobre esta tesis bien problemática: Jürgen Stolzenberg, Ursprung und System (citado en esta nota), p. 30 y ss. Cfr. En general sobre el papel del método trascendental en la filosofía del derecho de Kelsen: Stefan Hammer, “A Neo-Kantian Theory of Legal Knowledge in Kelsen's Pure Theory of Law?" (citado en la nota núm. 12), p. 181-183.

${ }^{91}$ Cfr. Paul Natorp, "Kant und die Marburger Schule", en Kantstudien, núm. 17, 1912, p. 193-221, especialmente las p. 196 y ss.

${ }^{92}$ Cfr. Heinrich Rickert, "Zwei Wege der Erkenntnistheorie" (citado en la nota núm. 59), p. 174, 193, 226; Heinrich Rickert, System (citado en la nota núm. 60), p. 144; Heinrich Rickert, Der Gegenstand der Erkenntnis (en lo sucesivo: Gegenstand), 3ª Edición, 1915, p. 244, $4^{\mathrm{a}}$ y $5^{\mathrm{a}}$ Edición, 1921, p. 212, 6a Edición, 1928, p. 240; Cfr. También: Eilhelm Windelband, "Normen und Naturgesetze", en Präludien (citado en la nota núm. 46), 1ª Edición, p. 219, 9ª Edición, Tomo II, p. 66.

${ }^{93} \mathrm{Cfr}$. Sobre las propias referencias de Kelsen a los dos componentes principales del método trascendental -el hecho presupuesto de la ciencia y una fundamentación "trascendental" de sus condiciones-, por ejemplo, Hans Kelsen, $R R 1$ (citado en la nota núm. 7), § 16 (especialmente la p. 37), así como $§ 29$ (especialmente las p. 66 y ss.). En relación con este aspecto es también muy instructivo en esta misma obra $\S 11$ (b) (p. 21-24). Cfr. Sobre este aspecto también: Robert Alexy, "Hans Kelsens Begriff des relativen Apriori”, en R. Alexy, L. H. Meyer, S. L. Paulson y G. Sprenger (Edt.), Neukantianismus und Rechtsphilosophie, Nomos, BadenBaden, 2002, p. 179-202.

${ }^{94}$ Hans Kelsen, Hauptprobleme (citado en la nota núm. 3), p. 121-188. Cfr. En general sobre este aspecto: Stanley L. Paulson, "Konstruktivismus, Methodendualismus und Zurechnung” (citado en la nota núm. 2). (Tiene traducción al castellano en: Stanley L. Paulson, "Constructivismo, dualismo metódico e imputación en la obra inicial de Hans Kelsen", en Id., Fundamentación crítica de la doctrina de Hans Kelsen, Traducción de Luis Villar Borda, Universidad Externado de Colombia, Bogotá, 2000.) 
decir, la doctrina de la determinación del objeto de conocimiento mediante la dirección del conocimiento.

Por una parte, debe mencionarse que la doctrina (3), junto con su doctrina de los dos mundos, puede considerarse como un reflejo de la distinción kelseniana entre las perspectivas aclarativa y normativa. Ello es así, porque la idea de que la dirección del conocimiento determina el objeto de conocimiento, significa, entre otras cosas, que la dirección o el método aclarativo del conocimiento determina un objeto en el primero de los dos mundos, mientras que la orientación normativa del conocimiento determina un objeto en el segundo mundo. Esto no significa, sin embargo, que la doctrina deba reconducirse a la escuela de Marburgo, sino, en caso de que ella pueda reconducirse de algún modo a una fuente filosófica ${ }^{95}$, a la escuela del Baden.

Por otra parte, y más allá del reflejo de la perspectiva y de la doctrina de los dos mundos de la escuela del Baden que está ligada a ella, es difícil vislumbrar, hasta qué punto la doctrina (3) representa algo más que una petición de principio. En la medida en que Kelsen aplicó una versión de la doctrina (3) en los trabajos de su etapa temprana -por ejemplo en la réplica a la "teoría de las dos facetas" de Jellinek" ${ }^{96}$, este autor admitió fácilmente la existencia de una correlación necesaria entre un método determinado y un objeto particular adecuado para ese método. Con fundamento en esta idea, Kelsen podía argumentar que era completamente falsa la afirmación de Jellinek según la cual, diversos métodos se relacionan con un objeto común ${ }^{97}$.

${ }^{95}$ Es problemático reconducir a una fuente filosófica esta doctrina en la forma tan poco detallada en que Kelsen la expone. Bruno Bauch señaló una vez que la tesis según la cual, la "correlación entre conocimiento y objeto" se reconduce a una referencia de Rudolf Hermann Lotz. Bruno Bauch "Das transzendentale Subjekt", en Logos 12, 1923/24, p. 29-49 (30). Otra posible fuente son las economías nacionales. En este ámbito se afrontó el "problema de la determinación del objeto". Con referencia a Kant, Windelband y Rickert se expresó así, por ejemplo, el economista Alfred Amonn: "El objeto de conocimiento, es decir, como un producto del acto de pensamiento aislado y abstraído, como una imagen puramente intelectual de un objeto de la experiencia fundamentalmente diverso y necesariamente separado, es aquél cuyo significado y particular importancia y singularidad está determinado por una ciencia”. Alfred Amonn, Objekt und Grundbegriffe der theoretischen Nationalökonomie, 1a . Edición, 1911, p. 21 (el énfasis es del original). El texto de la $2^{\mathrm{a}}$. Edición de la obra de 1925 aparece en la p. 25. La 1". Edición aparece en la serie "Wiener Staatswissenschaftliche Studien", en serie que en aquél entonces fue editada por Edmund Bernatzik, el profesor de Hans Kelsen. No puede excluirse la posibilidad de que fuentes de este tipo hubiesen jugado un importante papel en la recepción de la teoría (3) por parte de Kelsen.

${ }^{96} \mathrm{Cfr}$. Referencias en la nota núm. 33.

97 "Jellinek, y con él casi toda la nueva teoría del Estado, parte de la idea de que el Estado funciona como un mismo objeto, que unas veces constituye el objeto de la teoría social o sociología, y en otras ocasiones es el objeto de la ciencia jurídica. Jellinek señala literalmente: "para el conocimiento jurídico se trata sólo finalmente de la respuesta a la pregunta: cómo debo concebir jurídicamente al Estado?" Y sobre ello se opina: el mismo Estado que constituye el objeto de la sociología". Hans Kelsen, Der soziologische und der juristische Staatsbegriff 
Aún falta por analizar la doctrina (4), según la cual, el objeto de conocimiento surgiría lógicamente de un determinado origen. Por lo menos desde el punto de vista terminológico, esta doctrina refleja en algo la filosofía de Hermann Cohen. De acuerdo con Cohen, el pensamiento "no puede tener ningún origen fuera de sí mismo" "Y8 . Yl principio del origen de Cohen puede llamarse "principio del origen", porque -según la interpretación de Jürgen Solzenberg- "el solo pensamiento es el que posibilita producir la unidad entre legalidad y objetividad" $"$. Ahora bien, tan pronto se relaciona con Kelsen la doctrina del origen, la referencia a un "origen" remite de inmediato a la norma fundamental kelseniana. Los propios colegas de Kelsen en la escuela de teoría jurídica de Viena, Alfred Verfro $\beta$ y Felix Kaufmann, interpretan el concepto de "origen" exactamente de esta forma, es decir, en conexión con la norma fundamental. Refiriéndose a la terminología de Cohen sobre la "norma originaria" y la "hipótesis originaria" escribe Verdroß:

"La idea fundamental de la moderna teoría jurídica es el principio del orden jerárquico de los enunciados jurídicos en un sistema unitario sobre la base de una norma fundamental unitaria o serie fundamental. Como quiera que para los órdenes jurídicos estatales la Constitución del Estado (en sentido material aristotélico) representa el fundamento jurídico más alto, a partir del cual derivan su fuerza jurídica los demás enunciados jurídicos, también la norma fundamental se llama constitución o en terminología neokantiana norma originaria o hipótesis originaria" 100 .

La conexión antes mencionada entre la nomenclatura de la norma fundamental introducida por la escuela vienesa de teoría jurídica, con la terminología de Cohen de la "norma originaria" es insoslayable, por cuando Verdro $\beta$ correctamente la adscribe, en un comentario, a la obra Lógica del conocimiento puro de Hermann Cohen ${ }^{101}$.

Nada distinto ocurre con Felix Kaufmann. Este autor escoge el apelativo de "norma fundamental" y "no las expresiones "norma originaria" o "hi-

(citado en la nota núm. 22), § 20, p. 115 (el énfasis aparece en el original”, cfr. También $\S 18$ (especialmente la p. 106). La cita dentro de este texto de Kelsen proviene de: Georg Jellinek, System der subjektiven öffentlichen Rechte (citado en la nota núm. 23), p. 13 (el énfasis es de Kelsen). Cfr. En general sobre la problemática de la correlación entre método y objeto: Barna Horváth, Rechtssoziologie, 1934, p. 40-49.

${ }^{98}$ Hermann Cohe, Logik der reinen Erkenntnis, $2^{\text {a }}$. Edición, 1914, reimpreso con una introducción de Helmut Holzhey, 1977, p. 13.

${ }^{99}$ Jürgen Stolzenberg, Ursprung und System (citado en la nota 90), p. 53. Cfr. En general sobre este aspecto las p. 47-58.

${ }^{100}$ Alfred Verdro $\beta$, "Die gesellschaftswissenschaftlichen Grundlagen der Völkerechtstheorie", en Archiv für Rechts- und Wirtschaftsphilosophie, núm. 18, 1924/25, p. 413-431 (especialmente la p. 423) (el énfasis es del original) (con referencias, entre ellas una a Cohen), reimpreso en: WS 2 (citado en la nota 36), p. 2079-2095 (especialmente la p. 2088).

${ }^{101}$ Cfr. Ibíd.. 
pótesis originaria" que con frecuencia se encuentran en la obra de Kelsen, porque, pese al uso que Hermann Cohen hace del concepto de "origen" con estas expresiones, fácilmente puede ligarse a ellas una relación temporal que puede originar malos entendidos" ${ }^{\prime 102}$.

El propio Kelsen introdujo por primera vez en 1914 el término de "norma fundamental". ${ }^{103} \mathrm{Su}$ fuente de aquél entonces, la obra "Gesetz, Gesetzanwendung und Zweckmäßigkeitserwägung” (ley, aplicación de la ley y sopesamiento adecuado a los fines) del administrativista Walter Jellinek $^{104}$, se situaba bien lejos de la escuela de Marburgo. Este concepto, que entonces todavía no estaba concebido filosóficamente, significaba "norma presupuesta superior"105. Kelsen desarrolló con el tiempo esta norma de una manera filosófica cada vez creciente, a saber -según una interpretación- como medio para esquematizar su categoría normativa de la imputación ${ }^{106}$. En los trabajos que desarrolló hasta 1925, este autor utilizó la nomenclatura de "norma originaria", así como la de "norma fundamental"107, para al final limitarse únicamente al concepto de "norma fundamental"108.

Con todo, no existe ni una sola cita en la que Kelsen acoja el concepto de "origen" en el sentido de Cohen. Por el contrario, se encuentran numerosas citas de varios representantes de la escuela vienesa de teoría jurídica, en los que la "norma originaria" se equipara con la "norma fundamental" en el sentido de Kelsen. Esto permite enunciar la conclusión de que tampoco

${ }^{102}$ Felix Kaufmann, Die Kriterien des Rechts, 1924, reimpreso en 1966, p. 129 nota 2.

${ }^{103}$ Cfr. Hans Kelsen, "Reichsgesetz und Landesgesetz nach österreichischer Verfassung" en Archiv des öffentliches Rechts, núm. 32, 1914, p. 202-245, 390-438, especialmente las p. 215-220.

${ }^{104}$ Cfr. Walter Jellinek, Gesetz, Gesetzanwendung und Zweckmäßigkeitserwägung, 1913, p. 26-29. Kelsen habría seguido a Walter Jellinek (Cfr. nota 103) sin referirse expresamente a él. Sin embargo, Kelsen lo superó. Cfr. Hans Kelsen, Das Problem der Souveränität, 1920, p. 98, y con mayor explicitud: Hans Kelsen, "Rechtswissenschaft oder Rechtstheologie?", en Österreichische Zeitschrift für öffentliches Recht, núm. 16, 1966, p. 233-255, especialmente la p. 241.

${ }^{105}$ Hans Kelsen, "Reichsgesetz und Landesgesetz nach österreichischer Verfassung", (citado en la nota núm. 103), p. 217.

${ }^{106}$ Cfr. Stanley L. Paulson, "Hans Kelsen’s Doctrine of Imputation”, en: Ratio Juris, núm. 14, 2001, p. 47-63.

${ }^{107}$ Cfr. Hans Kelsen, Das Problem der Souveränität (citado en la nota núm. 104), p. VII, 8, (33 notas), p 48, 97 y ss.; Hans Kelsen, "Rechtswissenschaft und Recht", (citado en la nota núm. 82), p. 215, 231, 233, reimpreso en: Die Rolle des Neukantianismus (citado en la nota núm. 82), p. 391, 407, 409; Hans Kelsen, Allgemeine Staatslehre (citado en la nota núm. 21), $\S 19$, p. 99, § 20, p. 104, § 46 (c), p. 338.

${ }^{108}$ Cfr. Hans Kelsen, Die philosophischen Grundlagen der Naturrechtslehre und des Rechtspositivimus (citado en la nota núm. 55), § 4 (p. 12-14), § 12 (p. 25 ss.), §§ 35-37 (p. 63-72), reimpreso en: WS 1 (citado en la nota núm. 36), p. 286-288, 299 y ss., 337-345; Hans Kelsen, $R R 1$ (citado en la nota núm. 7), §§ 27-31 (a) (p. 62-76). 
la doctrina (4) puede reconducirse a la escuela de Marburgo de una manera que sea digna de mención.

También puede mostrarse que la existencia de una influencia de la escuela de Marburgo en el último objeto de la enumeración de Kelsen, la tesis de la identidad entre Estado y Derecho, es todo menos clara. Ello es así, porque el punto decisivo en esta tesis, es decir, que el Estado, en cuanto constituye objeto de conocimiento jurídico, sólo puede ser derecho ${ }^{109}$, puede entenderse como una aplicación de la correlación varias veces mencionada entre el método y el objeto de conocimiento. Kelsen aplicó una y otra vez esta correlación con gran convencimiento ${ }^{110}$, sin despertar la impresión de que para ello tuviese que aducir una fundamentación de teoría del conocimiento. Sobre este aspecto Kelsen no acepta de ningún modo la idea de Cohen en el prólogo a la $2^{\text {a }}$ Edición de los Problemas Capitales, en relación con la tesis de la identidad entre el Estado y el Derecho. Más bien, Kelsen lleva a cabo un mayor desarrollo conceptual de esta tesis, al que se refiere en la obra Das Problem der Souveränität (el problema de la soberanía), con base en un concepto unitario de persona. En esta obra, terminada ya en el año 1916, no se encuentra ni una sola huella de la escuela de Marburgo ${ }^{111}$.

Finalmente, Kelsen deja una impresión ambivalente e insegura frente a Hermann Cohen, en el único trabajo en el que alude brevemente a quien fue la cabeza de la escuela de Marburgo, "Rechtswissenschaft und Recht"112 (ciencia jurídica y derecho). Por ejemplo, Cohen intentó constituir la ética filosófico-trascendental sobre la existencia de la ciencia, en este caso de la ciencia del derecho. Kelsen, sin embargo, no está dispuesto a valorar positivamente la empresa de Cohen en general, así como tampoco en lo que concierne a la constitución filosófico-trascendental de la ética.

"La pregunta en la que Kant sintetizó sus problemas: de qué modo son posibles los juicios sintéticos, es equivalente a la pregunta de cómo es posible la experiencia, entendiendo la experiencia como ciencia, de cómo es posible la ciencia, entendiendo la ciencia como conocimiento y de cómo es posible el conocimiento. Sobre este preciso punto, cuando Cohen intentó aplicar el método trascendental más allá del ámbito de las ciencias naturales e intentó constituir la ética de modo filosófico-trascendental, también intentó que existiese una ciencia, cuyos juicios sintéticos debieran ser el objeto de ética trascendental a la

${ }^{109}$ Hans Kelsen, Hauptprobleme (citado en la nota núm. 3), $2^{\text {a }}$ Edición con un nuevo prólogo, 1923, p. XVII.

${ }^{110}$ Cfr. Por ejemplo, el texto que se encuentra en las notas 96 y 97.

${ }^{111}$ Sólo el prólogo a Problem der Souveränität escrito en la primavera de 1920 (citado en la nota núm. 104), V-IX, representa una excepción.

${ }^{112}$ Hans Kelsen, "Rechtswissenschaft und Recht" (citado en la nota núm. 82). 
lógica y análoga a una crítica analítica. La pregunta de si Cohen tuvo éxito con este intento, puede dejarse aquí sólo planteada." 113

En uno de los trabajos de Fritz Sanders que despertó la reacción de Kelsen en su trabajo "Rechtswissenschaft und Recht" (ciencia jurídica y derecho), Sander criticó agudamente a Cohen:

"El problema del conocimiento puro escapa de la especificación de las ciencias naturales, todas las cuales - matemática, mecánica, física y química- tienen como tarea la unidad de la naturaleza, el objeto de la naturaleza [...] Se plantea ahora la indeclinable pregunta de si cada científico cuyo objeto de crítica es la ética, contempla y debe contemplar como el objeto de su trabajo a un objeto unitario. Si la idea de la naturaleza es la objeto único sobre el que trabajan los científicos naturales, así mismo debería considerarse a la idea de humanidad como el único objeto del trabajo de los científicos que se dedican a la comunidad. ¿Cómo entonces, si es que acaso existen ciencias por fuera de las ciencias naturales, su objeto no es nunca o no puede ser nunca la idea de humanidad? ¿En qué sentido puede afirmarse que el objeto ideal de la ciencia jurídica es la idea de humanidad? ¿No tiene esta afirmación un trasfondo de derecho natural? Si, como afirma Cohen, la ciencia jurídica es la matemática entre las ciencias del espíritu, entonces debería existir la prueba de que así como los juicios matemáticos encuentran su relación con la existencia en las ciencias naturales matemáticas, los juicios científico-jurídicos únicamente podrían encontrar su cumplimiento concreto en las demás ciencias del espíritu. Sin embargo, esto es algo que no puede demostrarse. Por ello, para dar un ejemplo, no existe ninguna relación inmanente entre la ciencia del derecho y la economía". ${ }^{114}$

En otras palabras, Sander es escéptico de que pueda hablarse de un objeto unitario de las ciencias del espíritu (Hermann Cohen) o de las ciencias de la comunidad (Albert Görland) ${ }^{115}$. Kelsen suscribe esta crítica de Sander: "Lo que Sander objeta especialmente contra el intento de Cohen, es acertado en general" 116 .

En relación con esta posición escéptica frente a la teoría del conocimiento de Cohen, expuesta en el trabajo "Rechtswissenschaft und Recht" (ciencia jurídica y derecho), aparecido en 1922, sorprende encontrar un año después, en el prólogo a la segunda edición de los Problemas Capitales, una actitud entusiasta de Kelsen. Ahora bien, aceptar esta circunstancia como una razón favorable a la catalogación de su propia teoría jurídica en relación

${ }^{113}$ Ibíd. 128 (énfasis mío), reimpreso en: Die Rolle des Neukantianismus (citado en la nota núm. 82), p. 304.

${ }^{114}$ Fritz Sander, "Die transzendentale Methode der Rechtsphilosophie und der Begriff der Rechtserfahrung", en: Zeitschrift für öffentliches Recht, núm. 1, 1919/20, p. 468-507 (p. 474 y ss.) (El énfasis es del original), reimpreso en: Die Rolle des Neukantianismus (citado en la nota núm. 82), p. 75-114 (especialmente las p. 81 y ss.)

${ }^{115}$ Cfr. Albert Görland, Ethik als Kritik der Weltgeschichte, 1914.

${ }^{116}$ Hans Kelsen, "Rechtswissenschaft und Recht" (citado en la nota núm. 82), p. 128, reimpreso en: Die Rolle des Neukantianismus (citado en la nota núm. 82), p. 304. 
con la escuela de Marburgo, soslaya el hecho de que las citas a favor de la doctrina del neokantismo del suroeste o del Baden adoptada expressis verbis, el uso de una terminología común y la familiaridad de Kelsen con las obras de esta escuela, ofrecen argumentos que tienen un mayor peso.

A partir de todo lo anterior, que me autoriza a apelar a ciertas doctrinas de los neokantianos del Baden en conexión con la filosofía del derecho de Kelsen, me referiré de nuevo a la antinomia que surge de la doctrina de los dos mundos. Resolver dicha antinomia es una condición necesaria para poder defender la tesis débil de la normatividad.

\section{El sentido inmanente y el problema de la disolución de la antinomia}

Si se observa la doctrina de los dos mundos como un reflejo óptico equivalente de la distinción entre hecho y valor, con ello también se puede concluir que el rigor con el que se aplica puede extrapolarse a todos los niveles. Así procede Kelsen. Sin embargo, el tratamiento estrictamente análogo de las dos doctrinas llega demasiado lejos. Si se mantiene a cualquier precio la analogía y, como consecuencia, el abismo insalvable entre ambos mundos, se cae en una trampa.

Heinrich Rickert es consciente de ello. Este autor defiende la concepción de que no podemos

"limitarnos a extraer lo real como uno de los lados del mundo, para luego mostrar que los valores, que sería el otro lado, no pueden reconducirse a un ser real. Tenemos que preguntarnos por la relación que existe entre ambos reinos y entender qué es lo que los une" 117 .

Rickert expresa su solución, en la que se refiere a la existencia de un tercer mundo, un "tercer reino"118. El último problema del cual se debería ocupar la filosofía, sería el de la unidad entre los valores y la realidad, "y para ello la filosofía debe buscar un tercer reino, que conecta las dos regiones observadas hasta el momento intencionalmente de modo particular"119. Este tercer reino, sin embargo, no puede absorber en sí a los dos primeros, los reinos de los valores y de la realidad, porque si no dominaría un nuevo tipo de

${ }^{117}$ Heinrich Rickert, System (citado en la nota núm. 60), p. 233. Cfr. También Heinrich Rickert, "Vom Begriff der Philosophie" (citado en la nota núm. 60), p. 19, 21-23, 26 y ss., reimpreso en: Heinrich Rickert, Aufsätze (ctiado en la nota núm. 60), p. 21, 23-24, 28 y ss.

${ }^{118}$ Cfr. Heinrich Rickert, System (citado en la nota núm. 60), p. 254.

${ }^{119}$ Heinrich Rickert, "Vom Begriff der Philosophie" (citado en la nota núm. 60), p. 19, reimpreso en: Heinrich Rickert, Aufsätze (citado en la nota núm. 60), p. 21. En relación con este artículo, Johannes von Kries, Logik, 1916, p. 649 y ss, reaccionó escépticamente en relación con el tercer reino de Rickert. Sobre enfoques posteriores de Rickert, ante todo el intento de solucionar la problemática de la conexión apelando al sentido inmanente, lamentablemente von Kries no adoptó ninguna posición, a pesar de que los escritos correspondientes de Rickert ya habían aparecido antes de la obra "Logik". 
monismo en vez del dualismo originario. Las dos regiones unidas por medio de este tercer reino, tendrían que "permanecer protegidas en su singularidad, es decir, en cierto modo tampoco podrían estar unidas"120.

Entonces Rickert intenta asegurarse contra el peligro de que los dos reinos, el de los valores y el de la realidad, puedan desembocar en el tercero. Para ello, tan pronto introduce el tercer reino, lo debilita. Como quiera que "un tercer reino", que tuviese un rango óntico comparable con el de los dos primeros, socavaría el dualismo defendido por Rickert, este autor reemplaza la idea de un tercer reino con la de un reino fronterizo entre los dos existentes:

"Lo que buscamos para la comprensión de la unidad del mundo, sólo puede ser un reino fronterizo, es decir, una región intermedia entre lo válido y lo real, y de eso ya se sigue que no existe un tercer reino, que pueda existir de la manera en que existen los valores y la realidad. De otro modo sería absurdo. Estos dos mundo ya constituyen una alternativa. No puede pensarse entonces en producir su unidad mediante la construcción de otro nuevo mundo"121.

No obstante, el así llamado reino fronterizo no es más que una representación del problema de la conexión entre los dos mundos, que no consigue resolverlo. La solución que Rickert expuso en algunos de sus primeros trabajos y que luego desarrolló con mayor profundidad en sus obras capitales System der Philosophie (Sistema de la filosofía) y Gegenstand der Erkenntnis (El objeto del conocimiento), se debe a un análisis del concepto del sentido inmanente.

En Gegenstand der Erkenntnis (El objeto del conocimiento) Rickert profundizó en un teoría de tres partes sobre el acto y su contenido de sentido. En primer lugar, es posible diferenciar el acto como procedimiento psicológico, de su sentido. "Hay que escindir de la manera más estricta la 'mera'verificación psicológica de la existencia de un acto de enjuiciamiento, de su significado lógico." 122 Hasta aquí no hay nada sorprendente. Sin embargo, Rickert va mucho más allá en una segunda distinción. Este autor señala: "Debemos [...] escindir dos tipos de sentidos [...], a uno, el subjetivo, lo denominamos el sentido del acto, y al otro, el sentido objetivo, el sentido del objeto producido." ${ }^{123}$ La imagen que se tiene en los ojos con el sentido objetivo sería aquello que podría llamarse la "verdad del juicio", el

\footnotetext{
${ }^{120}$ Heinrich Rickert, System (citado en la nota núm. 60), p. 254 (el énfasis es del original).

121 Ibíd.

${ }^{122}$ Cfr. Heinrich Rickert, Gegenstand (citado en la nota núm. 92), $3^{\text {a }}$ Edición, p. 164 (el énfasis es del original), $4^{\mathrm{a}}$ y $5^{\mathrm{a}}$ Edición, p. 143, $6^{\mathrm{a}}$ Edición, p. 131; en esta cita y en las que se llevarán a cabo más adelante se hará alusión a la $6^{\mathrm{a}}$ Edición.

${ }^{123}$ Ibíd. (El énfasis es del original).
} 
contenido del juicio que existe para sí. Este debería concebirse desprendido del sentido inmanente al sujeto, puesto que -Rickert argumenta en este punto exactamente como Gottlob Frege 124 - "nosotros, todos en común, [...] opinamos y entendemos lo mismo, allí donde juzgamos o donde afirmamos que algo es verdadero." 125

En síntesis, esta teoría del acto y su contenido de sentido constaría de tres ámbitos. El primer ámbito, es decir, el acto en sentido psicológico, el ser psíquico real, que puede hacerse objetivo por métodos científicos, representa el primer mundo; el segundo ámbito, es decir, el contenido objetivo válido, representa un segundo mundo. El reino intermedio de Rickert es el del sentido inmanente. Las tres formas de pensamiento en que nos apoderamos de estos tres mundos respectivos, son el aclarar, el entender y el interpretar. ${ }^{126}$

Rickert opina que el sentido inmanente tiene una función de conexión frente a los otros dos ámbitos ${ }^{127}$. Pero, ¿en qué consiste en realidad esa función de conexión? La respuesta de Rickert sobre este aspecto es un poco oscura: el sentido inmanente, el sentido del acto, no sería un ser psíquico, ni un valor que tiene validez, "sino el significado para el valor inmanente al acto $\mathrm{y}$, en esta medida, la conexión y la unidad de ambos reinos"128. Ahora puede preguntarse si esta aclaración de Rickert brinda un poco más de claridad. La

${ }^{124}$ Cfr. Gottlob Frege, "Logik" (escrita entre 1879 y 1971), en: Id., Nachgelassene Schriften, Edt. por Hans Hermes, Friedrich Kambartel y Friedich Kaulbach, 1969, p. 1-8, especialmente, las p. 4 y 7; Gottlob Frege, "Der Gedanke. Eine logische Untersuchung”, en: Beiträge zur Philosophie des Deutschen Idealismus, núm. 1, 1918/19, p. 58-77, especialmente las p. 68 y ss., reimpreso en: Id., Logische Untersuchungen, Edt. por Günter Patzig, 4ª Edición, 1993, p. 30-53, especialmente la p. 42 y ss. Cfr. En general sobre este aspecto: Wolfgang Carl, Frege's Theory of Sense and Referente, 1994, p. 76-114 et passim. Sobre la compleja pregunta de si Frege debería adscribirse al neokantismo, cfr: Gottfried Gabriel, "Frege als Neukantianer", en: Kantstudien, núm. 77, 1986, p. 84-101; Hans-Johann Glock, "Vorsprung durch Logik: The German Analytic Tradition”, en German Philosophy since Kant, Edt. Por Anthony O’Hear, 1999, p. 137-166, especialmente las p. 156-161; Volker Peckhaus, "Kantianer oder Neukantianer? Über die Schwierigkeiten, Frege der Prilosophie seiner Zeit zuzuordnen", en Gottlob Frege. Werk und Wirkung, Edt por Gottfried Gabriel y Uwe Dathe, 2000, p. 191-209; Wolfgang Carl, "Frege-A Platonist or a Neo-Kantian?", in Building on Frege, Edt. Por Albert Newen, Ulrich Nortmann y Rainer Stuhlmann-Laeisz, 2001, p. 3-18.

${ }^{125}$ Heinrich Rickert, Gegenstand (citado en la nota núm. 92), 3ª Edición, p. 164 (el énfasis es del original), 4 ${ }^{\mathrm{a}}$ y $5^{\mathrm{a}}$ Edición, p. 143, 6 ${ }^{\mathrm{a}}$ Edición, p. 161. Cfr. También Heinrich Rickert, "Zwei Wege der Erkenntnistheorie" (citado en la nota núm. 59), p. 196; Heinrich Rickert, System (citado en la nota núm. 60), p. 113.

${ }^{126}$ Ibíd., p. 262.

${ }^{127}$ Cfr. Ibíd., p. 261-264, Cfr. También Heinrich Rickert, Gegenstand (citado en la nota núm. 92), $3^{\mathrm{a}}$ Edición, p. 166 y ss., $4^{\mathrm{a}}$ y $5^{\mathrm{a}}$ Edición, p. 145 y ss, $6^{\mathrm{a}}$ Edición, p. 163 y ss.

${ }^{128}$ Heinrich Rickert, System (citado en la nota núm. 60), p. 261. 
pregunta debe quedar abierta hasta que se aclare lo que debe entenderse por "significado inmanente para el valor".

En la primera edición de la Teoría Pura del Derecho, Kelsen somete determinados presupuestos para su filosofía del derecho a una aclaración de las ideas de Rickert antes citadas ${ }^{129}$. Al igual que Rickert, Kelsen diferencia el acto como procedimiento psicológico de su sentido: la norma jurídica como "contenido de sentido" sería algo distinto "al acto psíquico en el que éste se quiere o se idea"130. También en el prólogo a la segunda edición de los Problemas Capitales se expresa claramente esta diferencia: "el deber ser de las normas como un contenido de sentido específico se diferencia claramente del acto psíquico del querer, en especial del querer de la norma"131. En la obra de Kelsen se acepta el mismo esquema que se encuentra en la obra de Rickert, es decir, el esquema compuesto por el acto y su sentido objetivo. En este punto, al igual que sucede en la parte de la obra de Rickert que se le asemeja, no hay nada sorprendente. Gracias a las investigaciones de Johann Friedrich Herbart, Bernard Bolzado, Rudolf Hermann Lotze, Frege, el primer Edmund Husserl y otros autores, esta diferenciación se hizo bien conocida. ${ }^{132}$ En las palabras de síntesis de Rudolf Zochers:

"Debe retenerse la diferencia necesaria entre lo que se piensa y aquello mediante lo que se piensa, que se establece de la siguiente forma: los objetos irreales que tienen validez, como elementos del mundo lógico-objetivo, deben

${ }^{129}$ El presupuesto capital es que no puede estarse satisfecho con una mera "objetivación" del material de la ciencia jurídica - como Rickert lo entiende dentro de la teoría de la ciencia y como Adolf Julius Merkl y Kelsen lo aceptan para emprender un programa semejante, partiendo de la idea de un escalonamiento normativo (cfr. cita núm. 3)-. Cfr. sobre la objetivación en este sentido: Stanley L. Paulson, "Zwei Wiener Welter und ein Anknüpfungspunkt: Carnaps Aufbau, Kelsens Reine Rechtslehre und das Streben nach Objektivität", en: Logischer Empirismus und Reine Rechtslehre, Edt. por Clemens Jabloner y Friedrich Stadler, 2001, p. 137-190, especialmente las p. 174-188.

${ }^{130}$ Hans Kelsen, $R R 1$ (citado en la nota 7), $§ 5$ (p. 6).

${ }^{131}$ Hans Kelsen, Hauptprobleme (citado en la nota 3), 2a Edición con un nuevo prólogo, 1923, p. IX (el énfasis es del original).

${ }^{132}$ Johann Friedrich Herbart, Lehrbuch zur Einleitung in die Philosophie, 4a Edición, 1837, nueva edición con una introducción de Wolfhart Henckmann, 1997, §§ 13, p. 34 et passim; Bernard Bolzano, "Wissenschaftslehre", especialmente la primera parte, el primer apartado, en Id., Gesamtausgabe, Edt. por Jan Berg, tomo 11.1, 1985, §§ 19-33 (p. 103-176); Rudolf Hermann Lotze, Logik, 1er libro: Vom Denken, 3er libro: Vom Erkennen, 1880, reimpreso con la correspondiente introducción de Gottfried Gabriel, 1989; Gottlob Frege, Grundsätze der Arithmetik, Tomo 1, 1893, en el prólogo, las p. V-XXVI, especialmente las XIV-XXVI; Edmund Husserl, Logische Untersuchungen, Tomo 1: Prolegomena zur reinen Logik. También en la publicación: "Zwei Wege der Erkenntnistheorie" (citado en la nota 59), p. 195, nota 1, p. 227, así como en: Gegenstand (citado en la nota núm. 92), $3^{\mathrm{a}}$ Edición, p. 274-276, cita 1, en las ediciones $4^{\mathrm{a}} \mathrm{y}$

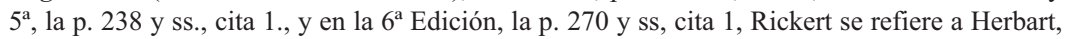
Husserl y sobre todo a Bolzano, así como a lo concerniente a la separación entre el sentido objetivo (o "trascendente") y el sentido práctico. 
separarse bien de los actos reales del pensamiento, que son el objeto del mundo psicológico-objetivo"133.

Sin embargo, al igual que ocurre en la obra de Rickert, Kelsen introduce una segunda diferenciación que va más allá. Se trata de la diferenciación entre el sentido inmanente-subjetivo y el sentido objetivo. Según Kelsen, es necesario

"distinguir entre el sentido subjetivo y el sentido objetivo de un acto. El sentido subjetivo puede coincidir con el sentido objetivo, aunque no es necesario que lo haga. El sentido objetivo incorpora al acto en el sistema de todos los actos jurídicos, es decir, en el sistema del derecho. Lo que hizo el conocido capitán von Köpenick era un acto, cuyo sentido subjetivo pretendía estar conforme con una orden administrativa. Desde el punto de vista objetivo, sin embargo, no se trataba de esto, sino de un delito." ${ }^{\text {"134 }}$

De acuerdo con Kelsen, el sentido subjetivo puede coincidir con el objetivo. Su solución a la problemática de la conexión, es decir, su solución a la antinomia consiste en la ya mencionada igualdad de contenido entre el sentido inmanente o subjetivo y el objetivo. ${ }^{135}$ Kelsen agrega inmediatamente que, como muestra acertadamente el ejemplo del capitán von Köpenick, no es imprescindible desde luego que un sentido coincida con el otro. Para producir una conexión entre los dos mundos, basta con que la coincidencia, es decir, la igualdad de contenido pueda tener lugar. ${ }^{136}$

¿Es entonces comparable la solución de Kelsen con la de Rickert, en el sentido de que Kelsen parte del mismo problema y de que, aunque sea en parte, lo presenta con los mismos conceptos que Rickert utilizó? Si se admite que el "significado inmanente" de la idea de Rickert sobre el "significado inmanente para el valor" es comparable con el sentido inmanente-subjetivo de Kelsen, entonces surge la pregunta de si la expresión "para el valor", que aparece en la idea de Rickert, puede entenderse como una referencia del sentido objetivo. Algunas razones hablan a favor de contestar esta pregunta de modo afirmativo.

En un punto de su obra, en el que Rickert introduce un tercer tipo de concepto de valor, este autor considera el sentido objetivo de un enunciado verdadero como un valor, "valor" que se refiere al nuevo concepto de valor que introduce:

${ }^{133}$ Rudolf Zocher, Die objektive Geltungslogik und der Immanenzgedanke, 1925, p. 9.

${ }^{134}$ Hans Kelsen, RR 1 (citado en la nota núm. 7), § 3 (p. 4).

135 También Rudolf Zocher expone en esta dirección una solución para la antinomia. Cfr. su monografía: Die objektive Geltungslogik und der Immanenzgedanke (citado en la nota 133), p. 18.

${ }^{136}$ Sin embargo, Kelsen no reconoce - hasta donde llega mi conocimiento- la igualdad de contenido que existe entre los sentidos inmanente-subjetivo y objetivo, como una posible manera de solucionar su antinomia. 
"si pensáramos con ello en ámbitos teoréticos de valores, es decir, en el sentido de enunciados verdaderos, no podríamos dudar al mismo tiempo de que también existen valores semejantes. El valor de la nutrición se basa en la valoración del hombre que quiere nutrirse, y así ocurre con todos los valores que llamamos hedónicos [...] Por el contrario, si no aceptamos el valor de un enunciado verdadero, tenemos que permanecer en ello. Este valor no sólo no necesita ser reconocido por todos, para tener validez "general" a pesar de ello, sino que tampoco es necesario que alguien sepa algo de él, para que a pesar de ello tenga validez, en el sentido de que todos los que quieran conocerlo, deban reconocerlo" 137 .

Rickert expresa de dos maneras que el sentido objetivo de un enunciado verdadero es un valor. Por una parte, se trata de entender como sinónimos, en la cita anterior, las frases "el sentido de un enunciado verdadero" y "el valor de un enunciado verdadero". La primera frase puede reemplazarse por la segunda frase y viceversa. Por otra parte, se trata de introducir el antes mencionado "argumento de Frege" -todos unidos opinamos y entendemos lo mismo, "cuando juzgamos o predicamos algo como verdadero"138 - en relación con ambas cosas: el sentido objetivo y el valor puro.

Con seguridad, una explicación completa de las relaciones entre el sentido y el valor en la filosofía de Rickert exigiría un análisis profundo de su teoría de los valores. Sin embargo, los textos de los cuales he tomado algunas citas, fundamentan una prueba prima-facie, de que los "valores" en el sentido de Rickert pueden relacionarse con el sentido objetivo.

Ahora puedo retornar una vez más a la idea de Rickert del "significado inmanente para el valor". "Significado inmanente" puede reemplazarse sin más en este contexto por "sentido inmanente" y, como acabo de argumentar, el término "valor" puede reemplazarse por el concepto de "sentido objetivo". Esta es exactamente la constelación que corresponde a lo que Kelsen plasmó con su solución basada en la posible igualdad de contenido. Si los reemplazos sugeridos son acertados, entonces el enfoque de Kelsen sería comparable con el de Rickert en el sentido aquí mencionado.

\section{Conclusión}

Desde el comienzo Kelsen luchó de forma impetuosa y consecuente contra la tesis de la facticidad o de la reducción. Su alternativa es la tesis débil de la normatividad. Esta es - ceteris paribus- una alternativa adecuada, por cuando la tesis débil de la normatividad sostiene que las normas jurídicas, como contenidos objetivos de sentido, no tienen su domicilio en

${ }^{137}$ Heinrich Rickert, System (citado en la nota núm. 60), p. 134 (el énfasis es del original), cfr. también la p. 261.

${ }^{138} \mathrm{Cfr}$. En este texto las citas 124-125. 
el mundo exterior del ser, sino en un segundo mundo, el mundo válido del deber ser. Sin embargo, a partir de la solución de este problema planteado con ocasión de la tesis de la facticidad, surge de inmediato un segundo problema: que los dos mundos permanecen uno frente a otro, separados por un "abismo insalvable". Kelsen intenta -al igual que Rickert expressis verbis- solucionar este segundo problema, apelando al concepto de sentido inmanente-subjetivo.

Este problema es desde luego muy profundo y tiene muchas aristas, y yo soy consciente de que los enfoques con los que Rickert y Kelsen construyen respectivamente su solución, plantean del mismo modo muchas preguntas que deben ser respondidas. Sin embargo, al mismo tiempo se ha mostrado que los dos pensadores se ocuparon de una empresa común. Este es un hecho que enfatiza el Leitmotiv de este artículo: también Hans Kelsen era un neokantiano. 